"BL VALOR MODAL REPORTATIVO DEL SUBJUNTIVO I AIBMAN"

En la Cludad de México, se presentaron a las 12,00 horas del dia 19 del mes de abril del aflo 2016 en la Onidad Iztapalapa de la Universidad Autónoma Netropolitana, 108 suscritos miembros del jurado:

DR. JOSE LBMA LAABADIE

DRA, MARIA ASELA REIG ATAMILLO

DRA. ESTHELA MARIA DEL SOCORRO TREVIRO CARZA

Bajo la Presidencia del primero y con caracter de Secretaria la bltima, se reunieron para proceder al Examen de Grado cuya denominación aparece al margen, para la obtención del grado de:

MAESTRO EN HUMANIDADES (IIMGDISTICA)

DE: JOSE ERNESTO COTA EARRADAS

$y$ de acuerdo con el articulo 78 fraccion III deI Reglasento de Estudios Superiores de la Universidad Aut bnoma Metropolitana, los niembros del jurado

\title{
APROBAR
}

Acto continuo, el presidente del Jurado comunico al interesado el resultado de la evaluacion $y$, en caso aprobatorio, le fue tomada la protesta. DIRECTOR DE SI Fै MAS ESCOLARES

DIRECTORA DE LADMISIÓN DE CSH

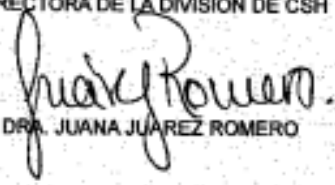

VOCAL

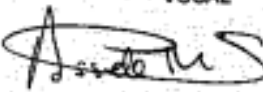

DRA. MARLAASEIA REIG ALAMILLO
PRESIDENTE

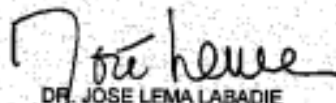

DF. JOSE LEMA LABADIE

SEGRETARIA

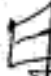

ADEL SOCORRO TREPNAOGARZA 


\title{
UNIVERSIDAD AUTÓNOMA METROPOLITANA \\ UNIDAD IZTAPALAPA \\ MAESTRÍA EN HUMANIDADES
}

\section{EL VALOR MODAL REPORTATIVO DEL SUBJUNTIVO I ALEMÁN}

\author{
Ernesto Cota
}

México D.F. febrero de 2016 


\section{Índice}

1. INTRODUCCIÓN 3

$\begin{array}{ll}1.1 \text { Objetivo } & 6\end{array}$

$\begin{array}{ll}1.2 \mathrm{El} \text { presente estudio } & 7\end{array}$

2. EL SUBJUNTIVO

2.1 El modo verbal en las oraciones complementantes 13

$\begin{array}{ll}2.2 \text { El subjuntivo alemán } & 17\end{array}$

$\begin{array}{ll}2.3 \text { El subjuntivo II alemán } & 18\end{array}$

$\begin{array}{ll}2.4 \text { El subjuntivo I alemán } & 20\end{array}$

2.5 El subjuntivo I en contraste con la forma II 26

3. MODO Y MODALIDAD 28

$\begin{array}{ll}3.1 \text { Modalidad } & 29\end{array}$

$\begin{array}{ll}3.2 \text { Modo } & 32\end{array}$

3.3 El indicativo y subjuntivo alemanes. Consideraciones sobre su modalidad 34

3.4 El subjuntivo I alemán y su carga de modalidad en el discurso indirecto 37

4. LA ALTERNANCIA ENTRE INDICATIVO Y SUBJUNTIVO I EN LA ORACION COMPLEMENTANTE DE ACUERDO A LA SEMÁNTICA DEL VERBO EN ALEMÁN 42

5. INDICADORES LÉXICO-SEMÁNTICOS DE MODALIDAD EN ALEMÁN Y SU INTERACCIÓN CON EL SUBJUNTIVO I

$\begin{array}{lr}\text { 6. Conclusiones } & 67\end{array}$

$\begin{array}{ll}\text { Bibliografía } & 71\end{array}$ 


\section{INTRODUCCIÓN}

En el ámbito de la lingüística descriptiva, recientes investigaciones han logrado identificar ciertos recursos gramaticales que algunas lenguas poseen para lograr determinados efectos pragmáticos. Se han identificado, por ejemplo, ciertas marcas o ítems léxicos que indican la actitud del hablante respecto a la información que comunica, por ejemplo, si la considera como verdadera, falsa, probable, entre otros valores. Otro tipo de marcadores, particularmente en lenguas con una rica morfología, tienen como función indicar la fuente de donde proviene la información que se anuncia, por ejemplo, si el hablante fue testigo directo del evento que comunica, o bien, si la información le fue reportada por una tercera persona; a este tipo de marcadores se le conoce como evidenciales. Asimismo existen marcadores para indicar si el hablante ha sido testigo visual o auditivo de los hechos que manifiesta. Otros marcadores permiten incluso indicar si el individuo obtuvo acceso al conocimiento del evento que comparte mediante un proceso de inferencia mental tomando como base ciertos indicios 0 pistas sobre la verificación del suceso referido.

En este punto es necesario advertir que no todas las lenguas poseen los mismos recursos gramaticales para indicar la actitud del hablante ante la información que desea comunicar, así que algunas lenguas recurrirán a marcadores morfológicos mientras que otras se valdrán del modo verbal para lograr un determinado efecto como sucede en alemán, lengua que posee dos formas diferenciadas del subjuntivo cada una con aplicaciones o funciones particulares. En los siguientes ejemplos podemos ver los verbos de las oraciones complementantes en indicativo, subjuntivo I y II. 
(1) a. Hans sagt, er ist glücklich. Juan decir.3SG.IND PRON.3.masc ser.3SG.IND feliz 'Juan dice que es feliz'

b. Hans sagt, er sei glücklich. Juan decir.3SG.IND PRON.3.masc ser.3SG.SBJV I feliz 'Juan dice que es feliz (pero yo no estoy seguro)'

c. Hans sagt, er wäre glücklich, wenn er Zeit hätte. Juan decir.3SG.IND PRON.3.masc ser.3SG.SBJV II feliz, COND PRON.3.masc tiempo tener.3SG.SBJV II 'Juan dice que sería feliz si tuviera tiempo'

Las oraciones complementantes de (1) son idénticas en cuanto a su contenido; en este caso concreto se trata de una aserción u opinión ajena al hablante que la comunica; nótese que la diferencia radica en la alternancia entre el modo indicativo y el subjuntivo. Este cambio de modo tiene efectos sobre la interpretación del evento que se anuncia: cuando el hablante recurre al indicativo como en (1a) se infiere que considera la noticia como un hecho verdadero: Juan dice que es feliz (y yo le creo); por el contrario, con el empleo del subjuntivo I (1b) se expresa cierta reserva respecto a la veracidad de la noticia: Juan dice que es feliz (pero yo no estoy seguro de ello). Es necesario mantener en mente este contraste de modos porque constituye el eje principal del trabajo; en breve, el indicativo señala que el juicio emitido es considerado como verdadero, mientras que con el empleo del subjuntivo I el hablante deja en claro que se trata de un juicio ajeno y no se responsabiliza sobre la veracidad del mismo. De esta observación se desprenden las siguientes preguntas que serán el eje del presente estudio:

1. ¿Qué implica la alternancia entre indicativo y subjuntivo I en las oraciones complementantes?

2. ¿Qué factores determinan la aparición del subjuntivo I en estas oraciones? 
3. ¿Se le puede asignar un valor de modalidad al empleo del subjuntivo I en este contexto de aparición?

A diferencia de lo que ocurre en alemán, en español el simple cambio de modo no resulta suficiente para determinar la actitud del hablante respecto al evento que comunica; por el contrario, el cambio de modo produce otras interpretaciones como se puede apreciar en las glosas: el indicativo español se elige para traducir tanto el indicativo como el subjuntivo I alemanes puesto que éste último no corresponde enteramente con el uso que tiene el subjuntivo español; en la glosa de (1c) aparece la forma del verbo ser en condicional para traducir el subjuntivo II alemán, el cual generalmente se asocia con situaciones hipotéticas o desiderativas en oraciones condicionales. En caso del subjuntivo II no se expresa ninguna actitud por parte del hablante respecto a la veracidad de la noticia referida como sucede cuando recurre al subjuntivo $\mathrm{I}$.

Es necesario advertir que, contrario a lo que pudiera pensarse y, en especial, si se compara con lo que sucede en español, en alemán el cambio del modo en las subordinadas como las de (1) obedece a una decisión consciente por parte del hablante y no depende, en un primer momento, del contexto sintáctico ni de la carga semántica del verbo principal. ${ }^{1}$ La alternancia señalada depende, más bien, de factores o determinantes pragmáticos relacionados con la noción de modalidad ${ }^{2}$ que analizaremos en el capítulo 3.

\footnotetext{
${ }^{1}$ En realidad como veremos más adelante el empleo del subjuntivo I por parte del hablante, aunque decisión consciente, no es del todo libre pues depende de otros factores que determinan su posible aparición o restricción.

${ }^{2}$ La cual podemos definir de momento como la actitud del hablante frente a la información que comunica.
} 
Si bien es cierto que el subjuntivo I tiene otras aplicaciones, se le encuentra por ejemplo en ciertas frases desiderativas e imperativas, actualmente la función que hemos destacado arriba es la que probablemente aparece con mayor frecuencia tanto en la lengua hablada como en la prensa, razón por la cual la hemos elegido como objeto de nuestro estudio. Cabe destacar que, contrariamente a lo que sucede con otras lenguas germánicas en donde las formas del subjuntivo prácticamente han desaparecido, con excepción del islandés, las dos formas del subjuntivo alemán resultan bastante productivas. En el caso concreto del subjuntivo I su empleo como indicador de un tipo concreto de modalidad parece consolidarse a la vez que pierde sus otros valores como se verá en el capítulo 2.

\subsection{Objetivo}

En algunos estudios sobre modo se ha sugerido que el subjuntivo I alemán conlleva cierto valor de modalidad (Palmer, 2001; Bybee et al. 1994). Sin embargo, la asociación que se hace entre el contexto discursivo donde aparece este modo y el valor modal que aporta no ha sido formalizada en términos que se relacionen con modalidad. Tampoco se ha demostrado si realmente el subjuntivo I posee valor modal por sí mismo o si, en última instancia, depende de la presencia de otros factores a nivel sintáctico que de manera conjunta expresen tal valor. Por lo anterior, el objetivo de nuestro análisis es identificar y caracterizar el valor modal del subjuntivo I para lo cual habremos de desarrollar los siguientes puntos:

a) Formalizar o definir claramente el concepto de modalidad para posteriormente establecer el matiz modal que aporta el subjuntivo I alemán.

b) Delimitar y esclarecer el contexto discursivo en el que aparece este modo verbal. 
c) Identificar otros elementos o factores que entran en juego cuando el subjuntivo I adquiere el valor modal que intentamos comprobar.

Como lo hemos mencionado, esta investigación se centra en una de las formas del subjuntivo alemán, en concreto la forma I, por lo cual será necesario recurrir a una breve caracterización de este modo; para ello tomaremos ejemplos del subjuntivo español, ejemplos que inicialmente no sólo servirán como contraste, sino que permitirán un acercamiento a las relaciones gramaticales que se establecen entre distintos componentes que se relacionan íntimamente con el empleo del subjuntivo I alemán. Al final, después de haber analizado los datos y realizado los contrastes pertinentes, estaremos en condiciones de contestar la pregunta de si es posible atribuir al subjuntivo I un valor de modalidad intrínseco o si éste depende de otros elementos dentro de un ambiente o contexto sintáctico-semántico que podríamos concebir como 'detonador de modalidad'.

\subsection{El presente estudio}

El presente estudio está organizado de la siguiente manera: en el capítulo 2 veremos algunas caracterizaciones que se han hecho del modo subjuntivo en general, así como también los usos particulares del subjuntivo alemán tanto de la forma I como de la II. Una vez que hayamos descrito el empleo del subjuntivo I e identificado el valor pragmático relacionado con nuestro objeto de estudio, podremos abordar la segunda parte de la investigación, capítulo 3 , que se centra en las nociones de modo y modalidad, dado que nuestro objetivo primordial es identificar y caracterizar el valor modal del subjuntivo I. 
A pesar de que el modo subjuntivo puede aparecer en oraciones independientes, el capítulo 4 contiene el análisis de la influencia que tiene la semántica del verbo principal sobre el modo que exhibe su oración subordinada. Con esto recordaremos al lector que existe una relación directa entre el verbo de la oración principal y el modo de la subordinada, fenómeno que es trascendental para nuestra investigación como lo demostraremos en el análisis propuesto. Para observar la alternancia de modo en las oraciones subordinadas realizaremos una clasificación particular de verbos, la cual está motivada por el hecho de que el subjuntivo I alemán aparece casi exclusivamente como complemento de un tipo concreto de verbos, mismos que se relacionan a su vez con un contexto discursivo particular. En el capítulo 5 describiremos los elementos o factores sintácticos que aparecen junto a la forma I para reforzar o cancelar el valor modal que buscamos categorizar.

Por último, deseamos justificar que nuestro estudio implica el análisis de varios componentes íntimamente relacionados, ya que consideramos que sería imposible descubrir el valor pragmático del subjuntivo I alemán si lo aislamos del contexto discursivo en que aparece, el cual, a su vez, se relaciona con una clase de verbos particulares y otros marcadores de modalidad.

\section{EI SUBJUNTIVO}

Dentro de los estudios clásicos se ha observado que el subjuntivo se encuentra relacionado con la actitud del hablante respecto a la información comunicada (RAE, 2010; Bello, 1847). No obstante, descifrar todos los mecanismos o factores que determinan su aparición requiere revisar cuidadosamente varios fenómenos que tienen lugar cuando el subjuntivo, por ejemplo, 
se puede oponer al indicativo, y, lo que es más intrigante aún, en ciertos contextos la alternancia indicativo-subjuntivo es posible sin que ello produzca resultados agramaticales. Uno de estos factores podemos encontrarlo en el carácter subyacente o supeditado que la misma denominación subjuntivo hace explícito, denominación que nos indica que existe cierta clase de dependencia o, mejor aún, conexión, entre los distintos elementos gramaticales que componen una oración principal y su correspondiente subordinada: particularmente la aparición del subjuntivo se ve condicionada en buena medida por la categoría semántica del verbo principal, aunque como se ha dicho existen otros factores que deben ser tomados en cuenta a la hora de encontrar una respuesta más satisfactoria en los intentos de categorización de este modo verbal.
a. Espero que tengas / *tienes oportunidad de venir.
b. Mi madre desea que festejemos / *festejamos su cumpleaños.
c. Pienso que *tenga / tiene razón.

En los ejemplos anteriores se puede afirmar que el verbo de la oración principal determina (2a, 2b) o bloquea (2c) la aparición del subjuntivo en la oración subordinada. No obstante, la carga semántica del verbo principal no es el único factor que establece el modo de la subordinada, por lo cual se deben tener en consideración otros factores de corte sintáctico y pragmático que al final determinan el modo que aparece en las oraciones complementantes. En ciertos estudios el modo verbal que exhibe la subordinada se ha tratado de explicar tomando en cuenta el carácter de realidad o irrealidad del evento referido (Lunn 1985), 
dicotomía que puede constituir un buen acercamiento ${ }^{3}$, pero que no ha logrado explicar de manera satisfactoria las numerosas excepciones que pueden presentarse como veremos posteriormente en nuestro análisis sobre la alternancia de modos en alemán. A pesar de la observación anterior, más adelante en nuestra investigación mencionaremos dos nociones de corte pragmático relativamente modernas que nos han permitido entender mejor el efecto que ejerce el verbo principal sobre el modo de la subordinada.

Como contraste de los ejemplos anteriores, el subjuntivo también se encuentra en oraciones independientes:
a. ¡Qué viva / vive el rey!
b. Ojalá sea / *es cierto.
c. Tenga / tiene usted cuidado.

En estos casos es conveniente que recurramos a un componente pragmático que nos permita explicar por qué el subjuntivo no sólo está permitido en esas oraciones sino que además rechazan el indicativo o, al menos, cuando éste aparece nos ofrece otra lectura. Los ejemplos en (3a) y (3b) se consideran como deseos o anhelos que expresa el hablante, mientras que el empleo del subjuntivo en (3c) tiene una lectura diferente, a saber, se trata de una petición u oración directiva. Esta observación ha llevado a algunos teóricos a suponer que el imperativo constituye en español un tercer modo verbal sin percatarse del hecho de que algunas de las formas del imperativo coinciden con las del subjuntivo (RAE, 2010); por consiguiente, aunque

\footnotetext{
${ }^{3}$ Dicotomía que se relaciona a su vez con la concepción tradicional que se ha tenido sobre los modos indicativo (real, certero) y subjuntivo (irreal, hipotético).
} 
en español algunas formas de subjuntivo y del imperativo pueden alternar entre sí, es necesario tener presente que sus aplicaciones y significados son distintos, advertencia que hay que tener presente cuando analicemos la fenomenología concreta del subjuntivo I alemán que buscamos describir. Pero ¿cuál sería entonces el elemento pragmático común a los tres ejemplos? La respuesta parece sencilla pero en realidad tras de sí existen varias nociones y consideraciones de corte pragmático y de tipología de las lenguas que se han venido desarrollando en los últimos años (Palmer 1980, Bybee et al. 1994). Podríamos decir, por ejemplo, que las tres oraciones reflejan desde la postura del hablante cierto matiz de irrealidad respecto al evento referido entendida ésta como una categoría ontológica y discursiva que expresa un evento que podría tener o no lugar en el mundo real, si no, se usa una declarativa negada; una consideración de la cual se pueden desprender varias posibilidades como las siguientes:

i. Es factible o posible que suceda en nuestro mundo real:

- Es probable que venga Juan a la fiesta.

ii. Es imposible que suceda (al menos en nuestro mundo) pero sí sería posible en un mundo imaginario del individuo:

- Si llueve café hago una fiesta.

iii. Se espera o anhela que suceda:

- Ojalá no suban más los precios.

iv. Se desea que no suceda:

- Anhelamos que no estalle ninguna guerra más. 
En resumen, las cuatro subcategorías anteriores comparten el rasgo de irrealidad del evento al que hacen referencia en el sentido de que reflejan un suceso que aún no se ha verificado; de esta observación se justifica que durante mucho tiempo el subjuntivo se haya caracterizado como el modo de lo hipotético o irreal. Sin embargo, cabe preguntarse si es correcta esta observación, es decir, ¿el subjuntivo expresa siempre irrealidad? ¿Qué decir de ejemplos como 'me alegra que hayas obtenido el empleo'?

Es interesante observar que los ejemplos con subjuntivo que hemos visto en la clasificación anterior se relacionan con sucesos potenciales que no han ocurrido, pero se espera que sucedan o al menos son posibles, por lo cual necesariamente debemos situarlos o ubicarlos dentro de una línea de tiempo en el futuro:

(4) a. Desearíamos que vinieras/ *vinieres más a menudo.

b. Ojalá tengas/ *tuvieres oportunidad pronto de visitarme.

c. A donde quiera que fueres, haz lo que vieres.

Nótese que para expresar estos eventos el español no utiliza el futuro del subjuntivo sino el pretérito (4a) o el presente (4b). El futuro, si bien prácticamente ha desaparecido, aún se conserva en algunas expresiones fosilizadas (4c). De cualquier forma, es claro que la relación entre frecuencia de empleo y los usos particulares del futuro del subjuntivo español no es el factor determinante en la aparición de esta forma en los ejemplos que hemos expuesto. 
En el siguiente apartado veremos con mayor detalle la variación del modo verbal de las oraciones subordinadas de acuerdo a la semántica del verbo principal, un hecho que resulta complejo de analizar puesto que, como hemos visto, existen otros condicionantes que entran en juego en la alternancia de modos tales como el componente pragmático y en última instancia la tipología particular de cada lengua 4 . No obstante, deseamos desarrollar este apartado como un acercamiento a nuestro análisis posterior porque, como el lector verá, la fenomenología propia del subjuntivo I alemán se relaciona en buena medida con dos clases particulares de verbos principales que propondremos posteriormente en el capítulo 4 .

\subsection{El modo verbal en las oraciones complementantes}

Como hemos dicho en el apartado anterior, las descripciones gramaticales han clasificado los modos indicativo y subjuntivo teniendo en cuenta casi exclusivamente la actitud del hablante como el factor determinante para la aparición de uno u otro modo en diferentes contextos sintácticos como aquellos que encabeza un verbo principal y su correspondiente oración complementante (RAE, 2010). En este tipo de oraciones es en donde se puede apreciar mejor el efecto que ejerce el verbo de la oración principal sobre el verbo subordinado:
a. Yo sé que Pedro llega / llegó esta noche.
b. Yo deseo que Pedro llegue / *llegara esta noche.

En los ejemplos anteriores hay que advertir que no es la actitud del hablante frente a la idea que comunica la que por sí misma determina la diferencia en el modo verbal de la oración

\footnotetext{
${ }^{4}$ Incluso en lenguas relativamente cercanas como el español y el alemán, el contenido semántico del verbo y la carga pragmática producen resultados distintos en la elección del modo verbal como veremos en este trabajo.
} 
complementante sino que este fenómeno se ha explicado históricamente haciendo hincapié en el nivel de certidumbre que por su contenido semántico refleja el verbo principal; por esta razón creemos que en oraciones subordinadas la actitud ante el evento o la idea comunicada no constituye en español, a diferencia de lo que ocurre explícitamente en alemán, un factor determinante, o por lo menos no lo suficientemente fuerte, que afecte directamente el modo del verbo subordinado, sino que éste obedece más bien a la categoría semántica del verbo principal como se puede apreciar en los ejemplos anteriores: (5a) contiene un verbo que indica conocimiento, el cual puede ser el resultado de un proceso inductivo sobre los antecedentes que se tienen sobre la posible realización del evento que se anuncia en la oración subordinada, mientras que en el caso de (5b) se trata de un verbo desiderativo que introduce una acción cuya ejecución escapa de la voluntad o control del hablante.

A modo de paréntesis y como contraste con lo que sucede en español —lengua donde la actitud del hablante parece que no muestra una influencia directa sobre la elección del modo en oraciones subordinadas, sino que más bien dicho modo depende de la semántica de la oración principal— se ha demostrado, en estudios tipológicos modernos sobre distintas lenguas que no pertenecen a la familia indoeuropea, que la actitud del hablante con respecto a la noticia que comunica efectivamente sí desempeña un papel crucial en la aparición de marcadores morfológicos de modalidad cuando ha escuchado una noticia, opinión o evento ajeno y que posteriormente desea comunicar ${ }^{5}$. Es importante destacar que un estudio más profundo de estas lenguas muy probablemente demostraría que la aparición de tal o cual partícula modal en diferentes contextos sintácticos no depende exclusivamente de la elección

\footnotetext{
${ }^{5}$ En concreto se han identificado morfemas que portan cierto valor de modalidad al indicar la fuente de donde se ha obtenido la información y/o la actitud del hablante respecto al evento referido.
} 
'arbitraria' por parte del individuo, por lo que en muchos caso podría tratarse en realidad de la confluencia de otros varios factores que actúan en conjunto como sucede en español, en donde hemos visto que la carga semántica del verbo principal ejerce una influencia importante sobre la elección del modo verbal de su oración subordinada.

Si volvemos al análisis del español vemos que en (6) la aparición del subjuntivo, y la agramaticalidad del indicativo, viene determinada por el valor semántico del verbo principal:

(6) Deseo que *está / esté bien.

Esta observación en realidad es muy antigua a tal punto que se han intentado explicar los contextos de aparición de los modos verbales, particularmente en las oraciones subordinadas, atendiendo exclusivamente al contenido semántico del verbo principal; para ello se han propuesto algunas clasificaciones que consideran, en efecto, únicamente la carga semántica del verbo como apreciamos en los siguientes ejemplos.

(7) a. La maestra pidió que los alumnos Ilegaran temprano.

b. Él considera que no tenemos otra alternativa.

c. La prensa anunció que se espera un alza en el precio de la canasta básica.

d. El pueblo anhela mejores condiciones de vida.

e. ¡Qué tengas mucho éxito!

f. Mi padre quiere que seamos responsables de nuestros actos. 
En los ejemplos $(7 \mathrm{a}, 7 \mathrm{~b}, 7 \mathrm{c})$ tenemos una oración complementante en donde el modo verbal depende del verbo principal. En (7d) no existe un verbo subordinado, aunque el verbo anhelar tiene satisfechos sus argumentos con el tema que actúa como su complemento; en (7e) la oración desiderativa aparece aislada y el modo que exhibe su verbo depende de otros factores que por el momento no mencionaremos; por último, en (7f) vemos una relación entre un verbo modal y su complemento. El análisis de la alternancia de modos en alemán que realizaremos posteriormente contempla básicamente los verbos que aparecen en los ejemplos (7a) y (7b), es decir, verbos que introducen un juicio u opinión ajeno.

Es importante reconocer que el proceso de selección que realiza el individuo dentro de su colección de ítems léxicos con respecto al verbo con el que introducirá su juicio puede ser considerado, desde luego, un hecho consciente y preciso; piénsense tan sólo en la diferencia radical que existe entre oraciones del tipo creo que está enfermo y afirmo que está enfermo. A pesar de que la oración subordinada es exactamente la misma, la actitud del hablante respecto a este juicio se refleja en la elección del verbo principal; en el primer caso evidentemente hay mayor incertidumbre con respecto a la idea que se comunica. Consideramos que esta observación es de suma importancia en el desarrollo de nuestra investigación, puesto que en alemán la elección de subjuntivo I, en contraposición con el indicativo, es un acto que el hablante realiza conscientemente y no depende únicamente del verbo principal que introduce el juicio que anuncia, sin embargo, en nuestro análisis en el capítulo 4 proponemos una clasificación de verbos que se encuentra motivada por la fenomenología concreta del subjuntivo I alemán. 


\subsection{El subjuntivo alemán}

El alemán posee dos formas del subjuntivo (Konjuntiv) I y II; esta división obedece más bien a los usos particulares que se pueden englobar en una y otra forma, y no se consideran como criterios de clasificación los tiempos o la morfología de cada una de ellas, no obstante, el subjuntivo I comparte la raíz con el presente de indicativo mientras que el subjuntivo II con el pretérito del indicativo:

\begin{tabular}{|l|l|l|l|}
\hline \multicolumn{1}{|c|}{$\begin{array}{c}\text { Presente de } \\
\text { indicativo }\end{array}$} & \multicolumn{1}{|c|}{ Subjuntivo I } & \multicolumn{1}{c|}{$\begin{array}{c}\text { Pretérito de } \\
\text { indicativo }\end{array}$} & \multicolumn{1}{c|}{ Subjuntivo II } \\
\hline ich komme & ich komme & ich kam & ich käme \\
\hline du kommst & du kommest & du kamst & du kämest \\
\hline er kommt & er komme & er kam & er käme \\
\hline wir kommen & wir kommen & wir kamen & wir kämen \\
\hline ihr kommt & ihr kommet & ihr kamt & ihr kämet \\
\hline sie kommen & sie kommen & sie kamen & sie kämen \\
\hline
\end{tabular}

Tabla 1. Paradigma flexivo del verbo kommen (venir) en presente y pretérito de indicativo, y las dos formas del subjuntivo. Nótese el cambio vocálico de la raíz en el caso del subjuntivo II.

En esta sección abordaremos primero el empleo que tiene actualmente el subjuntivo II alemán, y revisaremos cómo es posible englobarlo o categorizarlo de acuerdo con las nociones tradicionales que se han tenido sobre el modo subjuntivo. Posteriormente veremos que la forma I del subjuntivo alemán posee otras aplicaciones que merecen un acercamiento 
distinto en vista de que hoy en día su principal empleo está relacionado con ciertos elementos sintácticos y un fuerte componente pragmático.

\subsection{El subjuntivo II alemán}

En la didáctica de la lengua alemana, y en las correspondientes descripciones sobre los modos verbales en las gramáticas del alemán (Balcik, 2009), se ha mencionado que el subjuntivo II tiene principalmente los siguientes usos:

(8) i. Expresar irrealidad o una situación hipotética:

a. Wenn ich Zeit hätte, ginge ich auf die Party. COND 1SG tiempo tener.1SG.SBJV(II), ir.1SG.SBJV(II) 1SG a DET fiesta 'Si tuviera tiempo, iría a la fiesta'

ii. Hacer una petición de forma más cortés comparada con el efecto que se lograría empleando el indicativo:

b. Ich möchte eine Suppe.

1SG gustar.1SG.SBJV(II) DET sopa

'Quisiera una sopa', 'me gustaría una sopa'

iii. Expresar deseos:

c. Ich hätte gern mehr Zeit.

1SG tener.1SG.SBVJ(II) con gusto más tiempo

'Si tan sólo tuviera tiempo'

iv. En el caso del punto (i) la situación hipotética también se puede ubicar en el pasado:

d. Wenn ich meinen Regenmantel genommen hätte, wäre ich auf die Party gegangen.

COND 1SG POS.1SG.ACC abrigo tomar.PTCP haber.1SG.SBJV(II),ir.1SG.SBJV(II) 1SG a DET fiesta

ir.PTCP

'Si hubiese traído el abrigo, habría ido a la fiesta' 
De los empleos anteriores el primero (8a) es el que se puede relacionar directamente con el carácter de irrealidad del evento referido, cualidad que se le ha otorgado al modo subjuntivo en las lenguas romances. Además, hay que notar que este matiz hipotético es interno, es decir, forma parte de la consideración del hablante que emite el juicio, un juicio que al mismo tiempo le pertenece. En contraposición con esta observación, más adelante veremos que, en el caso del subjuntivo I alemán, es un factor determinante para su aparición el hecho de que los juicios que se comunican sean ajenos al hablante.

A diferencia de lo que ocurre en español, el alemán opta por el subjuntivo II tanto en la prótasis como en la apódosis (i); en español, el subjuntivo sólo ocurre en la prótasis (tuviera) mientras que el modo condicional aparece en la apódosis ${ }^{6}$ (iría). En los usos (ii y iii) al tratarse básicamente sobre expresiones de deseo, que desde el punto de vista temporal podrían verificarse en el futuro, la elección del subjuntivo II parece conveniente. En español igualmente se opta por el subjuntivo (quisiera) como aparece en (ii), aunque el condicional (gustaría) también se puede emplear en la traducción. Hay que observar que en estos ejemplos el potencial del español (iría, gustaría) aparece varias veces en la traducción, un hecho que demuestra, aunque quizás de manera indirecta, por qué se ha vacilado a lo largo de la historia de las gramáticas en ubicarlo bien dentro del indicativo o bien del subjuntivo ${ }^{7}$. Por último, en el caso de (iv) el modo elegido para el auxiliar es el subjuntivo (hubiese) junto con el condicional (habría) de la subordinada.

\footnotetext{
${ }^{6}$ La prótasis es la oración que contiene la condición: si vienes temprano, mientras que la consecuencia es expresada por la apódosis: vamos al cine.

7 Compárese, por ejemplo, la edición de 1917 de la Gramática de la RAE que contemplaba el potencial (cantaría) en el imperfecto del subjuntivo.
} 


\subsection{El subjuntivo I alemán}

Cuando abordamos el estudio del subjuntivo I alemán es importante destacar que son varios los factores que determinan su aparición en el acto discursivo, factores que se exponen en los siguientes apartados:

\section{I) La incertidumbre respecto al evento referido desde la perspectiva del hablante}

El subjuntivo I alemán tiene en la actualidad prácticamente un solo empleo: el hablante comunica una opinión o un juicio emitido por una tercera persona sin importar si lo ha escuchado de manera directa o no. El rasgo que determina esta forma discursiva es el valor que se desea otorgar a la información comunicada, a saber, cierto matiz de distanciamiento con respecto al evento comunicado, lo cual significa que el agente que comunica no se responsabiliza sobre la veracidad del juicio emitido.
a. Hans sagt,
er ist
krank. Juan decir.3SG.IND, 3SG estar.3SG.IND enfermo 'Juan dice que está enfermo'
b. Hans sagt, er sei krank. Juan decir.3SG.IND, 3SG estar.3SG.SBJV(I) enfermo 'Juan dice que esté enfermo'

En concreto, el empleo del subjuntivo I nos indica que la opinión expresada no pertenece a la del hablante sino a una tercera persona y, de manera conjunta a este efecto, queda claro que el hablante tampoco cuenta con evidencia sobre la veracidad de la información que comunica (9b); un efecto contrario a lo que sucedería si se empleara el indicativo (9a) en donde no existe el efecto de distanciamiento que hemos mencionado. 
En este sentido nos podemos formular la siguiente pregunta, ¿el subjuntivo I, al igual que la forma II, expresa una situación u opinión que se considera irreal o hipotética? Ciertamente la elección del subjuntivo por parte del hablante refleja esa duda o incertidumbre respecto el evento. No obstante, en el fondo no es ésta la función o carga principal que posee el subjuntivo I, sino más bien la de indicar cierto valor de modalidad por parte del hablante sobre el juicio emitido ${ }^{8}$.

\section{II) La alternancia entre indicativo y subjuntivo I de acuerdo a la actitud del hablante}

La actitud del hablante quizá sea el factor de mayor peso en la aparición del subjuntivo I en el acto discursivo. A diferencia de lo que ocurre en español donde la alternancia del indicativo con el subjuntivo es agramatical o da como resultado otra lectura $(10 b)^{9}$, en alemán el empleo del subjuntivo I por parte del hablante es en cierta forma arbitrario puesto que puede elegir libremente entre indicativo (10c) o subjuntivo I (10d) para expresar la información:

a. Juan (i) dice que está (ij) enfermo.

b. Juan (i) dice que esté ${ }_{\left({ }^{*} / j\right)}$ enfermo.

c. Hans (i) sagt, er ist $(\mathrm{i} j)$ krank. Juan decir.3SG.IND, 3SG estar.3SG.IND enfermo 'Juan dice que está enfermo'

d. Hans (i) sagt, er sei (ij) krank. Juan decir.3SG.IND, 3SG estar.3SG.SBJV(I) enfermo 'Juan dice que está enfermo (pero no me consta)'

\footnotetext{
${ }^{8}$ Aquí hemos introducido el principal uso que tiene el subjuntivo I alemán, pero el valor concreto de modalidad que aporta es analizado en el capítulo 3.

${ }^{9}$ En español si se emplea el modo subjuntivo en la subordinada, como en este ejemplo, el sujeto no puede ser entonces el mismo que aparece en la principal. En alemán la alternancia de modos no afecta la interpretación sobre el referente de los sujetos pudiéndose tratar del mismo sujeto o de dos distintos.
} 
El sujeto de la subordinada de (10a) puede ser correferencial con el de la oración principal, aunque también puede hacer referencia a otro sujeto cuya identidad se identificaría en el contexto discursivo. Lo importante aquí es notar que en español el empleo del subjuntivo no puede, al parecer, otorgar por sí mismo el carácter de modalidad que se obtiene con el mismo modo en alemán; en breve, la elección de indicativo o subjuntivo en español no nos informa nada sobre la actitud del hablante respecto el juicio emitido en el sentido de que considere la información como verdadera o falsa. Esto no significa, desde luego, que el hablante de español carezca de la posibilidad de tomar distancia con respecto al juicio que emite, sino que en español hay que recurrir a otros recursos para lograr tal efecto. En este punto es necesario hacer un par de aclaraciones sobre los ejemplos de (10) que permitirán al lector una mejor comprensión sobre el empleo del subjuntivo I alemán que estamos analizando. Como hemos visto, en la oración subordinada de (10a) el verbo aparece en indicativo como sucede en el ejemplo (10c) del alemán; cuando aparece este modo en la subordinada la interpretación sobre el sujeto nos indica que puede ser o no correferencial (i/j) con el de la oración principal (i); del mismo modo es necesario advertir que los sujetos, tanto de la oración principal como de la subordinada, son la tercera persona del singular o del plural pero no la primera 0 segunda persona; posteriormente en nuestro análisis veremos que esta fenómeno es fundamental en la caracterización del empleo del subjuntivo I alemán. La siguiente observación tiene que ver ahora con el modo subjuntivo de la subordinada; cuando éste aparece en español (10b) el sujeto de no puede ser correferencial $\left({ }^{*} \mathrm{i} / \mathrm{j}\right)$ con el de la oración principal (i); más aún, el empleo del subjuntivo en la subordinada le confiere a ésta una lectura de mandato u orden, es decir, se trata de una oración directiva, fenómeno que no sucede en 
alemán (10d) donde el sujeto de la subordinada puede seguir siendo o no (i/j) correferencial con el de la oración principal (i).

\section{III) La confluencia de elementos sintácticos y marcadores léxicos}

La presencia del subjuntivo I en las oraciones subordinadas que analizaremos se ve favorecida o restringida dependiendo de si en el contexto oracional existen otros elementos que pueden conjugarse entre sí para reforzar el matiz modal que el subjuntivo I aporta; aunque también es posible que alguno de esos elementos refleje este matiz de modalidad, de tal suerte que la presencia del subjuntivo I ya no es necesaria y su aparición se cancela. Advertimos que, más que adoptar o representar la función que podría tener el subjuntivo I, existen ciertos marcadores léxicos que tienen una función aproximada pero nunca exactamente la misma. Todos estos elementos los podemos dividir a su vez en tres grupos principales:

\section{A. El complementante dass (que)}

En alemán la oración subordinada puede ser introducida por el complementante dass (11a), aunque también es posible que no la encabece ningún ítem subordinante (11b) a diferencia de lo que ocurre en español donde el subordinante siempre es obligatorio a no ser que se citen las palabras de una tercera persona:
a. Hans sagt,
dass er krank
ist/sei.
Juan decir.3SG.IND, COMP 3SG enfermo estar.3SG.IND/SBJV(I)
'Juan dice que está enfermo' 

b. Hans sagt,
er ist/sei
krank.
Juan decir.3SG.IND, 3SG estar.3SG.IND/SBJV(I) enfermo
'Juan dice que está enfermo'

En los ejemplos de (11) tanto el indicativo como el subjuntivo están permitidos, no obstante, cuando el estilo de habla es más cuidado la ausencia del complementante dass no sólo favorece la aparición del subjuntivo, sino que también refuerza aún más el matiz de modalidad que aporta contrario a lo que sucedería por ejemplo si la subordinada estuviera encabezada por este complementante. Hay que entender que este reforzamiento se encuentra en relación directa con la lectura que ahora nos brinda la ausencia o presencia del complementante. En un apartado posterior explicaremos que el indicativo, el subjuntivo y dass se pueden combinar de diferentes maneras para producir lecturas igualmente distintas, a saber, el efecto logrado puede ser de carácter reportativo o citativo.

\section{B. La preposición laut (según, de acuerdo con)}

La sola presencia de laut invalida la aparición del subjuntivo (12b); es importante destacar que esta preposición por lo general no se emplea para introducir juicios u opiniones de una tercera persona $^{10}$, sino únicamente con el fin de hacer referencia a disposiciones, reglamentos 0 indicaciones que se encuentran asentadas por escrito en un documento de carácter oficial; en este caso el indicativo es el modo verbal que se prefiere (12a):

a. Laut des Vertrages, er hat das Recht sich krank
anzumelden

\footnotetext{
${ }^{10}$ A diferencia de lo que ocurre en español donde la preposición según sí puede introducir juicios ajenos. No obstante, como hemos indicado, en alemán esto no es común, razón por la cual oraciones del tipo Laut meines Freundes, er habe kein Geld, 'según mi amigo, (él) no tiene dinero' no son frecuentes en alemán.
} 
PREP DET.GEN contrato.GEN, 3SG tener.3SG.IND DET derecho PRON enfermo reportarse

'De acuerdo con el contrato, (él) tiene el derecho de reportarse enfermo.

b. Laut des Vertrages, er *habe das Recht sich krank anzumelden
PREP DET.GEN contrato.GEN, 3SG tener.3SG.SBJV(I) DET derecho PRON enfermo reportarse

'De acuerdo con el contrato, (él) *tenga el derecho de reportarse enfermo.

Justamente el carácter oficial de los documentos que son introducidos por laut nos puede brindar una pista de por qué el subjuntivo no está permitido: la disposición o reglamento se toma como fuente fidedigna de información por lo que la posibilidad de que el hablante introduzca duda o incertidumbre resulta poco práctica aunque se trate de una serie de disposiciones que no le pertenecen pero que, no obstante, puede comunicar a una tercera persona como si se tratara de un juicio ajeno.

\section{Indicadores léxicos de modalidad}

Muchos adverbios, en alemán y otras lenguas, pueden reforzar los matices de certeza o incertidumbre respecto al juicio emitido por lo cual consideramos que su análisis se relaciona con el subjuntivo I. En un apartado posterior demostraremos que estos indicadores generalmente tienden a bloquear la aparición del subjuntivo I; en (13) el adverbio vermutlich (supuestamente) entra en conflicto con el subjuntivo I:

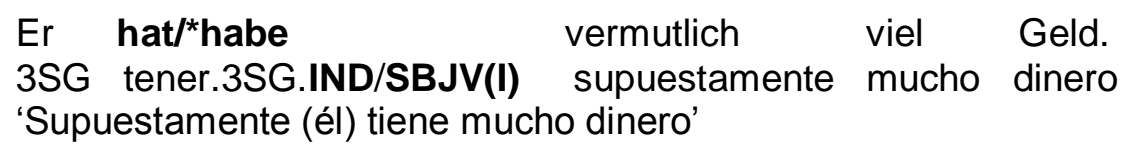




\subsection{El subjuntivo I en contraste con la forma II}

A lo largo de este capítulo hemos delimitado y explicado brevemente las formas del subjuntivo alemán, sin embargo, también es necesario mencionar que una y otra forma no resultan intercambiables en sus aplicaciones básicas:
a. Hans sagt,
er hätte
gern
viel Geld. Juan decir.3SG.IND, 3SG tener.3SG.SBJV(II) con gusto mucho dinero

'Según Juan, a él le gustaría tener mucho dinero'

b. Hans sagt, er habe

viel Geld. Juan decir.3SG.IND, 3SG tener.3SG.SBJV(I) mucho dinero

'Según Juan, él tiene mucho dinero'

$\begin{array}{lcccc}\text { c. Hans sagt, } & \text { er } & \text { hat } & \text { viel } & \text { Geld. } \\ \text { Juan decir.3SG.IND, 3SG } & \text { tener.3SG.IND } & \text { mucho } & \text { dinero }\end{array}$
'Juan dice que tiene mucho dinero'

Si bien es cierto que en (14a) el subjuntivo II se permite, éste nos ofrece una lectura completamente distinta de la que tiene la forma I en (14b). El primer ejemplo podríamos parafrasearlo como a Juan le gustaría tener mucho dinero; nótese que aquí no está presente el efecto de distanciamiento que hemos mencionado anteriormente. Aun así, es probable que el matiz de irrealidad del propio evento (un deseo) sea suficiente para dejar en claro que se trata de una opinión o juicio ajeno. En cambio, en el segundo ejemplo el matiz de distanciamiento se logra perfectamente con el sólo empleo del subjuntivo I. Por último, en (14c) aparece el indicativo el cual por sí mismo no puede lograr tal efecto, así que la lectura podría ser como sigue: Juan dice que tiene mucho dinero (y estoy seguro de que así es o por lo menos comparto la opinión de Juan). 
En ocasiones las formas del subjuntivo I pueden reemplazarse por las formas equivalentes del subjuntivo II; no obstante, es necesario advertir que son únicamente las formas morfológicas las que son sustituidas pero no el efecto. Este reemplazo ocurre, con excepción de algunos verbos que tienen formas bien diferenciadas para todos los modos, con la primera y la tercera persona del plural dado que en estos casos las formas del subjuntivo I son idénticas a las del indicativo:
a. Hans sagt,
wir haben
viel
Geld. Juan decir.3SG.IND, 1PL tener.3SG.IND 'Juan dice que tenemos mucho dinero'
mucho dinero
b. Hans sagt,
wir haben Juan decir.3SG.IND, 1PL tener.3SG.SBJV(I) 'Juan dice que tenemos mucho dinero'
viel Geld. mucho dinero
c. Hans sagt, wir hätten
viel Geld. Juan decir.3SG.IND, 1PL tener.3SG.SBJV(II) mucho dinero 'Según Juan, tenemos mucho dinero'

En (15a) y (15b) vemos que no hay diferencia morfológica en los verbos cuando se trata del indicativo y subjuntivo I respectivamente; si ambas formas son idénticas se recurre entonces al subjuntivo II (15c). A pesar de este reemplazo, la lectura o el efecto de distanciamiento que lograría el subjuntivo I se hace presente y puede quedar aún más claro por el contexto discursivo donde se inserta la oración. De cualquier forma es poco probable que exista confusión o ambigüedad sobre la interpretación del juicio emitido: en este caso se sobreentiende que se trata de la opinión de Juan (sujeto principal) pero no de la nuestra (sujeto subordinado), así que el parafraseo podría ser: según lo que dice Juan, nosotros tenemos mucho dinero. 


\section{MODO Y MODALIDAD}

Para entender plenamente el valor del subjuntivo I alemán que buscamos esclarecer es necesario que revisemos ahora los conceptos de modo y modalidad que serán de especial importancia para nuestro análisis. La relevancia de estas nociones se encuentra respaldada por los resultados de diversos estudios tipológicos de varias lenguas del mundo en el ámbito de la lingüística funcional, ya que se ha demostrado que algunas de estas lenguas poseen marcadores morfológicos y sintácticos cuyas funciones se relacionan o corresponden con el empleo que tiene actualmente esta forma del subjuntivo alemán. Las funciones que presentan estos marcadores se pueden agrupar de manera generalizada de la siguiente manera:

i. Indican la postura del hablante respecto a la información que comunica.

ii. Indican la fuente de tal información.

La primera de estas funciones básicamente corresponde a lo que nosotros posteriormente definiremos como modalidad. Ahora bien, es importante destacar que si bien durante las décadas de los 70 s y 80 s se realizaron varias propuestas para clasificar los tipos de modalidad, especialmente tras la obra de Palmer (1986), en realidad estas clasificaciones obedecían en última instancia al deseo de explicar o agrupar de una manera sistemática los marcadores de cada lengua en particular, por lo que dichas clasificaciones variaban de un autor a otro y, lo que es más, el concepto de modalidad parece que nunca quedó del todo comprendido o por lo menos lo suficientemente claro; apenas en nuestros días es cuando tenemos a la mano planteamientos más precisos sobre el fenómeno de la modalidad. Con todo, no se cuenta aún con un consenso sobre modo y modalidad, de manera que algunos 
autores consideran que no hay diferencia alguna entre ellos y emplean los términos de manera indistinta. Para nosotros, no obstante, será necesario separar y explicar de manera precisa cada uno de estas nociones, ya que así lo requieren los objetivos de nuestro trabajo.

\subsection{Modalidad}

Más recientemente ciertos autores como Bybee, Perkins y Pagliuca (1994) realizaron interesantes propuestas sobre los distintos tipos de modalidad en las lenguas objeto de su análisis. Tal y como había sucedido con los primeros estudios en este ámbito, la clasificación que ellos propusieron estuvo motivada en muchos sentidos por los resultados que obtuvieron y la tipología particular de cada lengua estudiada, por lo que carecían de una caracterización o planteamientos más generales que pudieran aplicarse a todas las lenguas. Como hemos dicho, Palmer ya había llevado a cabo una exposición bastante extensa sobre las diferentes clases de modalidad, su empleo y otras características particulares en diversas lenguas, sin embargo, la obra de Palmer no es del todo original, pues toma como base las propuestas de otros autores que ya habían realizado un análisis tipológico de la modalidad. Curiosamente en todos estos estudios salta a la vista la carencia de una definición clara y concisa sobre modalidad a partir de la cual se pueda realizar un análisis más adecuado de los marcadores de modalidad en distintas lenguas; el mismo Palmer cita a Comrie para mencionar que "a diferencia de lo que ocurre con el tiempo y el aspecto que se relacionan con el evento, la modalidad tiene que ver con el estatus de la proposición que describe el evento" (Palmer, 2001). Sólo de manera muy reciente diversos artículos han retomado la cuestión de la modalidad de manera más clara y esquematizada como lo hacen de Hann (2001) y von Fintel (2006); éste último propone la siguiente definición de modalidad que adoptaremos para nuestro trabajo: 
"El estatus que tiene la proposición emitida por el hablante, es decir, la postura que toma el individuo con respecto a la información que comunica". (von Fintel, 2006)

Esta definición invariablemente nos lleva a preguntarnos cuáles serían los posibles valores que es factible otorgarle a la información que es comunicada. Por ejemplo, de acuerdo con los resultados obtenidos de los estudios tipológicos mencionados anteriormente se pueden encontrar valores tales como verdadero, falso, posible, probable, entre otros. Una alternativa para responder a esta interrogante, y que al mismo tiempo nos permite un acercamiento a nuestro objeto de estudio, es tomar como criterio base la propuesta inicial que justamente ha servido para categorizar los modos verbales en las lenguas romances como el español, es decir, la dicotomía real-irreal, puesto que como vimos en el capítulo sobre el subjuntivo, esta propuesta se ajusta, aunque no siempre, a las descripciones que se han hecho sobre el subjuntivo alemán particularmente la forma II. De esta manera podríamos entender entonces la propuesta de von Fintel como el juicio de valor que el hablante tiene sobre la información que comunica en el sentido de juzgarla como un hecho que ya ha tenido lugar (real), o bien, como una acción que puede suceder pero aún no se ha verificado (irreal). ${ }^{11}$

No obstante, como hemos advertido en el capítulo 2, la caracterización de los modos indicativo y subjuntivo bajo la dicotomía real e irreal resulta problemática en lenguas como el español porque numerosas excepciones no se ajustan a lo que dicho planteamiento propone como se aprecia en los siguientes ejemplos:

\footnotetext{
${ }^{11}$ Reconocemos, sin embargo, que la propuesta de von Fintel puede tener varias aplicaciones de acuerdo a la tipología de cada lengua y no únicamente la distinción entre real e irreal.
} 
(16) a. Dijo que la niña está bien.

b. Espero que la niña esté bien.

c. Supongo que la niña está / *esté bien.

d. Mañana vendrá / *viniera Pedro.

En (16a) el verbo de la oración complementante aparece en indicativo puesto que el hablante toma la noticia como un hecho real y probablemente se ha cerciorado personalmente de ello; esta idea podría parafrasearse como "digo que la niña está bien porque la he visto hace cinco minutos, es decir, me consta". Por el contrario, en (16b) el verbo esperar refleja incertidumbre, desconocimiento, por lo que la elección del subjuntivo en el complementante no representa un problema para la división propuesta sobre la realidad de los hechos. ¿Pero qué decir de un verbo como suponer? Por su contenido semántico es innegable que este verbo no puede expresar una entera certeza, ya que como hablante no se está seguro sobre la veracidad de la proposición que se supone, sino que ésta pertenece al ámbito de las especulaciones, sin embargo, en español la elección del subjuntivo en la oración complementante resulta agramatical como aparece en (16c). Una posible explicación tendría que tomar en cuenta, por ejemplo, la carga semántica del verbo y el conocimiento pragmático que tiene el hablante sobre el hecho que comunica. En efecto, aunque se emplee un verbo con matiz de incertidumbre para el hablante la idea que comunica puede ser algo real aunque no lo haya comprobado personalmente, ya que su certeza se puede basar en las deducciones e indicios que previamente habría realizado sobre el juicio emitido. Por último, el ejemplo (16d) pone de relieve la contraposición entre indicativo y subjuntivo, entre real e irreal, y nos parece conveniente para entender la diferencia entre realis e irrealis y el concepto de modalidad. Al 
tratarse de un hecho que no ha tenido lugar, puesto que sucederá en el futuro, no se puede tomar como real, y aquí hay que ser claros, no es real simplemente porque no ha sucedido, no obstante, como se ve la elección en el complementante del subjuntivo, el modo de la irrealidad, resulta agramatical.

\subsection{Modo}

De acuerdo con de Haan el modo es la gramaticalización de la modalidad ${ }^{12}$, es decir, todos las categorías gramaticales que sirven para expresar la postura del hablante respecto a la información que comunica. Mientras que la modalidad se puede concebir entonces como una noción pragmática, el modo se relaciona con los recursos morfológicos, sintácticos y semánticos de la lengua para expresar la modalidad deseada, por ejemplo, existen lenguas que dentro de su morfología requieren de marcas especiales que indican no solamente la actitud del hablante frente al hecho referido sino también la fuente o la manera de cómo se ha obtenido la información que se comunica como lo muestra el siguiente ejemplo:

\section{(17) Juse irida di-manika-pidaka José fútbol 3.SG.masc.sing-jugar-REC.P.REP 'José jugó fútbol (nos dijeron)'}

En (17) tenemos un ejemplo de arawak, una lengua del noroeste del Amazonas, en la cual el sufijo pidaka funciona como una marca que indica la fuente de donde se ha obtenido la información. En este caso en particular la información le fue comunicada al hablante por una tercera persona por lo cual este sufijo indica una nueva subcategoría llamada reportativo. Es

\footnotetext{
12 De Haan, Ferdinand (2005), Typological approaches to modality, en W. Frauley (ed.), Modality, Berlin: Mouton de Gruyter.
} 
importante indicar que este sufijo parece ser obligatorio y su omisión podría dar lugar a otra interpretación y, lo que es más, este ejemplo nos lleva a otra categoría pragmática, la de evidencialidad, es decir la fuente que el hablante tiene sobre la información que comunica (Aikhenvald, 2006). Una primera división de la evidencialidad trata la fuente de información como directa si el hablante vio o fue testigo directo del hecho que comunica o indirecta si el hablante infirió el evento a partir de su conocimiento de los hechos o si una tercera persona le refirió el acontecimiento. Con todo, esta propuesta no es del todo innovadora; ya Matthews (1965) había sugerido ciertas categorías que él reconocía dentro de la noción de modalidad aunque no las clasificaba como evidenciales; esta propuesta se basa en los resultados que obtuvo tras el análisis de la lengua Hidatsa, la cual tiene un sistema de morfemas que aparecen al final de oración y cuya función es indicar la postura del hablante con respecto a la proposición:

Enfático: indica que el hablante sabe que la oración es verdadera; si una oración que termina con (el morfema) enfático es falsa, el hablante es considerado un mentiroso.

Periodo: indica que el hablante cree que la oración es verdadera; si no fuera verdadera significa que el hablante cometió un error pero no se le considera un mentiroso.

Citativo: indica que lo que ha comunicado el hablante es un hecho conocido por todos.

Reportativo: indica que el hablante recibió la información que comunica de alguien más (y no directamente) pero no tiene evidencia de su valor (verdadero).

Indefinido/Pregunta: ambos indican que el hablante no sabe si la información es o no verdadera. El indefinido también indica que el hablante sabe que el oyente desconoce la información; por su lado la pregunta indica que el hablante piensa que el oyente conoce la información. 
Si bien es cierto que todas las categorías anteriores, en efecto, se pueden considerar como posturas del hablante respecto a la información que comunica, y por ende categorías modales, el concepto de reportativo, al indicar que la fuente de información es ajena al hablante, marca un punto donde inciden modalidad y evidencialidad. Justamente el hecho de que la evidencialidad se pueda subsumir dentro la modalidad ha llevado a algunos a pensar que las estrategias de evidencialidad pueden constituir una gran subcategoría modal. Sin embargo, el hecho no es tan simple como parece puesto que dependiendo de la lengua modalidad y evidencialidad pueden funcionar de manera independiente como lo pretende demostrar Aikhenvald tras sus estudios tipológicos.

\subsection{El indicativo y el subjuntivo alemanes. Consideraciones sobre su modalidad.}

Como ya se ha mencionado en la primera parte de este capítulo, el criterio que busca definir la diferencia entre modo indicativo y subjuntivo es el carácter de realidad o irrealidad que se supone que cada uno expresa de manera unívoca (Bybee et al. 1994). Aunque este planteamiento puede servir como un primer acercamiento para el análisis tipológico del modo, también hemos visto que la propuesta no está exenta de dificultades al intentar explicar o predecir el comportamiento sintáctico de las oraciones complementantes en las cuales, a su vez, entran en juego otros factores como la semántica del verbo principal y los núcleos funcionales, por ejemplo la negación, que en conjunto determinan en última instancia la elección de uno u otro modo. Conforme avanzaron los estudios tipológicos en las lenguas del mundo, se intentaron definir otras nociones, de carácter más bien pragmático, que pudieran dar cuenta de manera más satisfactoria del entorno en que pueden aparecer el modo indicativo y subjuntivo, como aquellas que propusiera Lunn (1995): 


\section{Aserción vs. No aserción}

Si bien esta propuesta no es del todo original, puesto que se puede considerar producto de una tradición que inició Bolinger (1968), se tiene como la más sucinta de todas. Lunn propone la dicotomía aserción ${ }^{13}$ - no aserción para explicar el contexto de ocurrencia del indicativo (aserción) o el subjuntivo (no aserción); sin embargo, esta propuesta falla cuando intenta explicar la aparición del subjuntivo en alemán como se verá en los siguientes ejemplos. Lunn considera un enunciado como no asertivo si cumple con alguna de las siguientes características:

I. El hablante duda de su veracidad:
a. $\mathrm{Er}$
sagt,
er sei klug. 3M.SG decir.3SG, 3M.SG ser.3SG.SBJVI listo 'Él dice (según él) que es listo'

b. Ich zweifle daran, dass $d u$ das Problem allein lösen kannst. 1SG dudar.1SG, COMP 2SG DET problema solo resolver poder.2SG.IND 'Yo dudo que puedas resolver el problema solo'

En (18a) la aparición del subjuntivo en la oración complementante concuerda con la propuesta de Lunn. En efecto, el hablante no sólo duda de la veracidad de la información sino que la elección del subjuntivo I en este contexto conlleva una fuerte carga de modalidad puesto que su función es tomar distancia con respecto a la proposición comunicada; en este sentido la elección del subjuntivo indica que el hablante no está seguro de la veracidad de la proposición que comunica. Por el contrario, en (18b), aunque la semántica del verbo principal expresa

\footnotetext{
${ }^{13}$ Este término tampoco está exento de debate. Cruse (2011) toma la propuesta del filósofo Searle y de manera sucinta define la aserción como "el compromiso (commitment) que tiene el hablante respecto a la verdad de la proposición expresada". Además, de acuerdo con Searle, algo que puede acertarse puede creerse, conocerse, dudarse.
} 
duda, vemos que en la oración complementante aparece el indicativo; así pues, aun cuando el hablante dude de la veracidad de la proposición, el alemán elige el indicativo para su complemento. Este es un hecho que resulta significativo, ya que constituye un contraste respecto al español que toma el subjuntivo para la misma oración subordinada.

II. La proposición no ha tenido lugar:

a. Ich hätte gern ein Auto.

1SG tener.1SG.SBJV II ADV DET auto

'Yo tendría con gusto un auto'

b. Ich benötige, dass du mir mein Buch zurückgibst. 1SG requerir.1SG.IND, COMP 2SG.NOM 1SG.DAT POSS libro devolver.2SG.IND

'Necesito que me regreses el libro'

En (19a) el verbo principal aparece en subjuntivo II, y en vista de que se trata de un deseo (que no se ha realizado) la aparición de este modo encaja perfectamente con la propuesta de Lunn. Por el contrario en (19b), y una vez más en contraste con el español, el modo del verbo de la oración complementante es el indicativo a pesar de tratarse de un hecho que no ha tenido lugar puesto que se formula una petición.

III. La proposición se presupone ${ }^{14}$.

a. Ich bin froh, dass du die Wahrheit kennst. 1SG ser.1SG feliz, COMP 2SG DET verdad conocer.2SG.IND 'Estoy feliz de que sepas la verdad'

\footnotetext{
${ }^{14}$ Recuérdese el concepto de aserción en el cual la veracidad de la proposición comunicada se toma como un compromiso, es decir, la veracidad de un hecho estaría en contraposición con la presuposición del mismo en donde el hablante carece de certidumbre respecto al mismo.
} 

b. Es
ist
gut,
dass du
gestern
gekommen
ayer
PTCP-venir
bist.
'Es bueno que hayas venido ayer'
AUX-ser-2SG.IND

Los dos ejemplos de (20) exhiben el indicativo en sus oraciones complementantes a pesar de que se espera la aparición del subjuntivo de acuerdo con la propuesta de Lunn. Una vez más es un hecho que contrasta con el español como se puede notar en las glosas. En conclusión, hasta este punto del análisis las dicotomías de realis - irrealis y aserción - no aserción no han podido predecir de manera satisfactoria los contextos en que aparecen el modo indicativo y subjuntivo en alemán.

\subsection{El subjuntivo I alemán y su carga de modalidad en el discurso indirecto}

Dentro de los estudios de la gramática alemana se ha dicho que uno de los usos principales del subjuntivo I alemán es expresar el discurso indirecto que incluso algunos han llamado reportativo (Fabricius-Hansen y Johan Saebö 2004). Por su lado Beristáin, dentro de la retórica, define el discurso indirecto de la siguiente manera:

"El discurso indirecto requiere la existencia de un narrador a cuyo cargo está relatar, describir las acciones de los personajes, y presentar sus parlamentos traspuestos (...) el mismo (el narrador) dice lo que el personaje dijo antes. Dice los hechos en lugar de mostrarlos, en un proceso enunciador que está dirigido por la conciencia unificadora del emisor, y que introduce una distancia entre el lector y los hechos de la historia". (Beristáin, 2003)

Esta definición, no obstante, no cubre de manera satisfactoria la descripción de la función que tiene el subjuntivo alemán en lo que se ha dado a llamar el discurso indirecto, puesto que 
carece de un punto fundamental, el distanciamiento del hablante. Por esta razón proponemos una nueva definición que dé cuenta del valor del subjuntivo en el discurso indirecto:

"En el discurso indirecto el hablante comunica una proposición que ha escuchado previamente al acto de habla sin importar si fue de manera directa o si la información la obtuvo de alguna otra fuente. El punto relevante aquí, y que se relaciona con el empleo del subjuntivo, es que, respecto a la información que comunica, el hablante toma distancia respecto al juicio emitido en el sentido de que no se responsabiliza por la veracidad o falsedad del mismo".

Discurso indirecto en subjuntivo l:

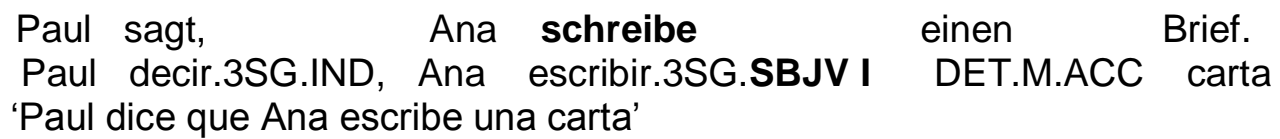

(Balcik (2009): 274)

En (21) el verbo de la oración complementante aparece en subjuntivo lo que ayuda a reforzar la distancia con respecto a la información que el hablante comunica, es decir, la noticia no se acepta como real o falsa, simplemente se enuncia lo que alguien más ha dicho (reportativo). Por el contrario, la elección del indicativo tendría el efecto pragmático contrario: el hablante toma como un hecho real la noticia que anuncia tal y como aparece en (22). Es justamente este efecto de "distanciamiento" lo que hace que el subjuntivo alemán sea un recurso utilizado abundantemente en la prensa alemana.
Paul sagt,
Ana schreibt
einen
Brief.
Paul decir.3SG.IND, Ana escribir.3SG.IND DET.M.ACC carta
'Paul dice que Ana escribe una carta'

(ibídem)

Aunque no hay duda de que el hablante tiene el recurso de elegir entre indicativo y subjuntivo al momento de comunicar una proposición para determinar su postura con respecto a la 
información emitida, nuestro objetivo principal, como hemos dicho, es caracterizar el valor de modalidad del subjuntivo I. Incluso podríamos aventurarnos más y preguntarnos si la forma del subjuntivo I se encuentra en proceso de gramaticalizarse y convertirse enteramente en un marcador de modalidad al tiempo que pierde sus otros valores tal y como sucede con los marcadores de modalidad en otras lenguas. Con el fin de responder adecuadamente a estas interrogantes será necesario tomar en cuenta las siguientes observaciones que retomaremos al final de nuestro análisis en el apartado de discusión.

I. El subjuntivo I alemán no aparece exclusivamente en el discurso indirecto. Se le encuentra en ciertas expresiones desiderativas, aunque se les puede considerar como ya fosilizadas (establecidas por el uso).

a. Lebe

der

König!

vivir.3SG.SBJV I DET.M.NOM rey

¿Qué viva el rey!'

b. Gott sei Dank!

dios ser.3SG.SBJV I agradecimiento

‘¡Gracias a Dios!'

II. El subjuntivo I aparece también en oraciones directivas, aunque actualmente en el habla cotidiana está restringido al verbo sein (ser, estar) como en (24a). También puede aparecer en manuales donde se indiquen instrucciones (24b); este uso prácticamente ha desaparecido.
a. Sei
bitte
vorsichtig!
ser.3SG.SBJV I por favor cuidadoso
‘¡Por favor, sé cuidadoso!' 


$\begin{array}{cclll}\begin{array}{c}\text { b. Man } \\ \text { Beispiel Fluor }\end{array} & \text { nehme } & \text { einen } & \text { kräftigen } & \text { Oxydator, zum } \\ \text { PRON.IMPER } & \text { tomar.3SG.SBJV I } & \text { DET.M.ACC } & \text { fuerte.M.ACC } & \text { oxidante, para } \\ \text { ejemplo flúor. } & & & \end{array}$

'Se toma un potente oxidante, por ejemplo flúor'

(Fabricius-Hansen (2004): 217)

III. Más interesante aún, el subjuntivo no aparece exclusivamente en oraciones complementantes de los verba dicendi (decir, contar, narrar) como tradicionalmente se había sugerido, sino que también pueden aceptarlo los complementos de verbos que indiquen opinión, creencia, imaginación, temor, deseo, etc. (Fabricius-Hansen, $2004)^{15}$. En otros verbos como criticar o alabar, el subjuntivo tendría un efecto pragmático sobre el complemento: si estos verbos adoptan el indicativo tendrían una interpretación de factividad (objeto de la proposición) como en (25a), mientras que el subjuntivo cancelaría el carácter factivo al señalar el contenido de la proposición (25b).

(25) a. Einstein kritisierte

nie, dass Bohr voreilig die Kasualität aufgegeben hatte.

Einstein criticar.3SG.PST nunca, COMP Bohr prematuramente DET.F casualidad rendir.PTCP haber.3SG.PST.IND

'Einstein nunca criticó que Bohr haya sacrificado la casualidad prematuramente'

\begin{abstract}
b. Einstein kritisierte, dass Bohr voreilig die Kasualität aufgegeben habe.

Einstein criticar.3SG.PST, COMP Bohr prematuramente DET.F casualidad rendir.PTCP haber.3SG.PRES.SBJV I

'Einstein nunca criticó que Bohr hubiese sacrificado la casualidad prematuramente'
\end{abstract}

${ }^{15}$ Sin embargo, la misma Fabricius-Hansen sugiere que con el uso del subjuntivo tales verbos deberían considerarse más bien como verba dicendi. 
IV. Una propuesta similar a la de Fabricius de Hansen es la de Elisa Kellner (2013), quien intenta explicar el uso del indicativo y del subjuntivo en el mismo entorno con la ayuda de una escala en cuyo extremo factivo aparecería el indicativo, reforzado por el complementante dass (que); el otro extremo, el asertivo, tomaría el subjuntivo sin dicho complementante:

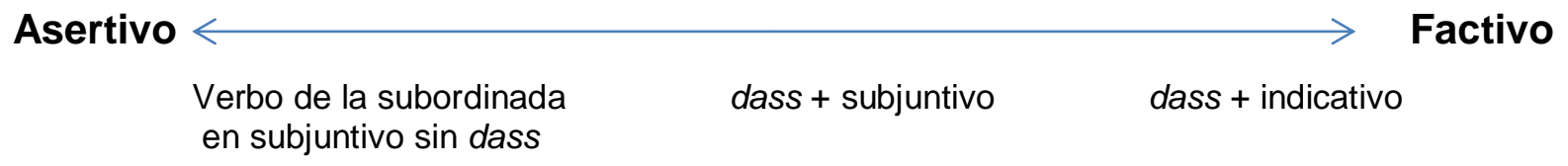

En el siguiente capítulo retomaremos las ideas sobre de factividad y asertividad, debido a que nos han permitido una mejor delimitación del funcionamiento concreto del subjuntivo I alemán tal y como quedará demostrado cuando realicemos capítulo donde realizaremos el análisis sintáctico de los verbos que inducen o restringen la aparición del subjuntivo I en sus oraciones complementantes. 


\section{LA ALTERNANCIA ENTRE INDICATIVO Y SUBJUNTIVO I EN LA ORACIÓN COMPLEMENTANTE DE ACUERDO A LA SEMÁNTICA DEL VERBO EN ALEMÁN}

En esta sección se pondrá de relieve el efecto que tienen algunos verbos del alemán, agrupados de acuerdo a algunas propiedades semánticas pertinentes, sobre la alternancia que existe a nivel sintáctico en cuanto a la elección del modo verbal en sus oraciones complementantes.

En vista de que analizaremos el contenido semántico que determina la elección de modo de la oración subordinada como predicado verbal, proponemos dividir los verbos que exigen este tipo de complementos en cinco grupos principales:

Verbos reportativos ${ }^{16}$ como sagen, mitteilen, informieren. (decir, compartir, informar) Verbos desiderativos como wollen, wünschen, hoffen. (querer, desear, esperar) Verbos dubitativos como bezweifeln, vermuten, scheinen. (dudar, suponer, parecer) Verbos de opinión como denken, glauben, meinen. (pensar, creer, opinar) Verbos exhortativos como bitten, beantragen, flehen. (pedir, solicitar, rogar)

Nuestro análisis inicial considera el contenido semántico de los verbos, el cual, de acuerdo con la clasificación anterior, debería determinar a su vez el modo que adoptan los verbos que aparecen en sus oraciones complementantes ${ }^{17}$. Tomaremos entonces como punto de partida el criterio base que hemos mencionado en los primeros capítulos y que se ha visto tradicionalmente como el factor que determina el modo verbal que aparece en las oraciones subordinadas para descubrir si en efecto las descripciones que se han realizado sobre el

\footnotetext{
${ }^{16}$ Verbos reportativos o verba dicendi, es decir, los verbos del acto de decir, comunicar.

17 Como se verá más adelante en nuestro análisis, la clasificación semántica de los verbos no es suficiente para predecir siempre de manera satisfactoria el modo verbal que adopta la oración complementante.
} 
contexto de aparición del indicativo y subjuntivo resultan adecuadas cuando analicemos el comportamiento de los verbos alemanes. La descripción del modo indicativo y subjuntivo tradicionalmente ha sido la siguiente:

- Modo indicativo: enuncia el hecho como real y objetivo desde la perspectiva del hablante.

- Modo subjuntivo: indica un hecho como subordinado a otro verbo que exprese deseo, temor, voluntad, suposición, etc.; es decir, se puede considerar como el modo de lo irreal o hipotético.

De acuerdo con el criterio anterior únicamente los verbos reportativos deberían inducir el modo indicativo en sus oraciones complementantes, ya que por lo general estos verbos se emplean para reportar o informar un hecho considerado por el hablante como real u objetivo. Si bien la presuposición y otros recursos pragmáticos pueden influir en la elección del modo verbal como sucede en español, por el momento dejaremos de lado esta consideración puesto que no es necesaria para el presente análisis sintáctico.

a. Hans sagt, der Kuchen schmeckt/schmecke gut. ${ }^{18}$ Juan decir.3SG.IND, DET pastel saber.3SG.IND/saber.3SG.SBJV I bien 'Juan dice que el pastel sabe bien'

b. Die Presse teilte mit, der Politiker hat/ habe eine ernste Krankheit.

DET prensa comunicar.3SG.PST.IND, DET político tener.3SG.IND/ tener.3SG.SBJV I DET seria enfermedad

'La prensa comunicó que el político padece una enfermedad grave'

c. Die Sekretärin informierte uns heute morgen, der Leiter der Firma kommt/komme nächste Woche zurück.

\footnotetext{
${ }^{18} \mathrm{~A}$ menos que se indique la fuente todos los ejemplos son del autor.
} 
DET secretaria informar.3SG.PST.IND PRON.1PL.DAT hoy mañana,

DET director DET empresa regresar.3SG.IND/regresar.3SG.SBJV I próxima semana atrás

'La secretaria nos informó esta mañana que el directo de la empresa regresa la próxima semana'

En los ejemplos de (26) los verbos de la oración principal son reportativos; sus oraciones complementantes pueden contener cierto tipo de modalidad reportativa (Matthews, 1965), es decir, el hablante comunica una opinión o noticia que fue emitida por alguien más pero no toma responsabilidad sobre la veracidad de la misma. Este fenómeno obedece al hecho de que este tipo de verbos permite la alternancia entre indicativo y subjuntivo $\mathrm{I}^{19}$ en el verbo de la oración subordinada; es justamente esta alternancia lo que refleja modalidad reportativa: si el verbo aparece en indicativo se considera que el hablante toma como verdadero el hecho que comunica, mientras que el empleo del subjuntivo refleja o conlleva una lectura de modalidad reportativa, es decir, no hay responsabilidad moral sobre la veracidad o falsedad del evento comunicado de acuerdo con la propuesta de Matthews. ${ }^{20}$

Ahora veremos el comportamiento de los verbos desiderativos, lo cuales, según el criterio que mencionamos al inicio, deben elegir de manera predeterminada el modo subjuntivo para sus oraciones complementantes dado que indican deseos o eventos que no han tenido lugar; por consiguiente la elección del modo indicativo debe formar oraciones agramaticales:

a. Der Lehrer wünscht, dass du morgen kommst/*kommest.

DET maestro desear.3SG.IND, COMP tú mañana venir.3SG.IND/venir.3SG.SBJV I 'El maestro desea que vengas mañana'

${ }^{19}$ El alemán posee dos formas del subjuntivo: I y II. No obstante, en el presente análisis se considera únicamente el subjuntivo I porque es el que tiene prominencia en el discurso indirecto en alemán como se explicó en el capítulo I.

20 Matthews (1965) Reportativo: indica que el hablante recibió la información que comunica de alguien más (y no directamente) pero no tiene evidencia de su valor (verdadero). 
b. Der Chef will, dass du alles mögliches machst ${ }^{*}$ machest.

DET jefe querer.3SG.IND, COMP tú todo posible hacer.3SG.IND/ hacer.3SG.SBJV I 'El jefe quiere que hagas todo lo posible'

c. Wir hoffen darauf, dass du viel Erfolg in deiner Arbeit hast/ *habest.

nosotros esperar.1PL.IND PREP, COMP tú mucho éxito en POS.2SG.DAT trabajo tener.3SG.IND/ tener.3SG.SBJV I

'Esperamos que tengas mucho éxito en tu trabajo'

Como se comprueba en los ejemplos de (27) en todos los casos el empleo del subjuntivo resulta agramatical. En alemán esta clase de verbos desiderativos aceptan únicamente el indicativo en sus oraciones subordinadas; un hecho que no concuerda con el criterio que mencionamos inicialmente sobre la aparición del subjuntivo en formulaciones de deseos o anhelos. ${ }^{21}$ Si seguimos con este mismo razonamiento los verbos dubitativos también deberían mostrar el modo subjuntivo y no el indicativo en sus complementos:

a. Sie vermutet, dass er kein Geld hat/*habe. ella suponer.3SG.IND, COMP él ningún dinero tener.3SG.IND/tener.3SG.SBJV I 'Ella supone que él no tiene dinero'

b. Es scheint, dass der Hund noch krank ist/*sei. PRON.3SG.NEUT parecer.3SG.IND, COMP DET perro todavía enfermo estar.3SG.IND/ estar.3SG.SBJV I

'Parece que el perro aún está enfermo'

c. Er befürchtet, dass der Patient nicht mehr leben kann/*könne. él temer.3SG.IND, COMP DET paciente NEG más vivir poder.3SG.IND/poder.3SG.SBJV I

'Él teme que el paciente no pueda vivir más (no logre vivir)'

\footnotetext{
${ }^{21}$ No obstante, en oraciones condicionales que expresan deseos sí es posible el uso del subjuntivo tanto en la prótasis como en la apódosis: wenn du morgen kämest, würde ich mich freuen (si vinieras mañana, me alegraría). Hay que notar, sin embargo, que estas formas pertenecen al subjuntivo II y no al I, forma que analizamos en este apartado.
} 
A pesar de que los verbos que indican duda hacen referencia a hechos no confirmados, sino más bien a consideraciones hipotéticas, todos los verbos principales de (28) eligen únicamente el modo indicativo para sus oraciones complementantes, es decir, la alternancia entre indicativo y subjuntivo en esta clase de subordinadas no es posible.

Es momento de analizar el comportamiento de los verbos de opinión, los cuales, de acuerdo al criterio de partida, deben inducir el modo indicativo en vista de que se piensa y opina aspectos de la realidad que se consideran como objetivos y certeros aunque es innegable que la duda puede estar presente en el juicio de la persona que lo formula. Veamos cómo reaccionan los siguientes ejemplos:

a. Der Zeuge glaubt, der Entführer ist/sei schon tot. DET testigo creer.3SG.IND, DET secuestrador ser.3SG.IND/poder.3SG.SBJV I ya muerto

'El testigo cree que el secuestrador está muerto'

b. Mein Vater denkt, mein Bruder kommt/komme morgen. mi padre pensar.3SG.IND, mi hermano venir.3SG.IND/venir.3SG.SBJV I mañana 'Mi padre piensa que mi hermano vendrá mañana'

c. Die Kunstkritiker meinen, alle Da Vincis Meisterwerke sind/seien wunderschön.

DET críticos de arte opinar.3PL.IND, todas Da Vinci. GEN obras maestras ser.3SG.IND/poder.3SG.SBJV I maravilloso

'Los críticos de arte opinan que toda la obra artística de Da Vinci es maravillosa'

Si este tipo de verbos comunica ideas o juicios que se consideran verdaderos, la elección del modo indicativo está plenamente justificada por nuestro criterio inicial. El modo subjuntivo, no obstante, no produce resultados agramaticales si tales oraciones se encuentran en el contexto del discurso indirecto. Por ejemplo en (29a) el reportero que estuvo presente en el interrogatorio que le fue realizado al testigo, y que posteriormente comunica la noticia, elegiría 
preferentemente el subjuntivo I porque con ello no toma parte en la opinión del testigo, es decir, la proposición anunciada adopta un matiz de modalidad reportativa de acuerdo con la propuesta de Matthews. Desde esta perspectiva los verbos de opinión están relacionados con los verbos reportativos porque ambos grupos pueden aparecer en el discurso indirecto.

Por último, haremos el análisis con los verbos exhortativos. Al tratarse de peticiones o ruegos la información contenida en la oración complementante se considera como un hecho probable pero que no ha tenido lugar, por ello, la elección del modo subjuntivo es esperada así como la exclusión del indicativo:

a. Paul bittet Ana, sie *soll/solle einen Brief schreiben. Paul pedir.3SG.IND Ana, ella deber.3SG.IND/poder.3SG.SBJV I DET carta escribir 'Paul le pide a Ana que escriba una carta'

[Balcik, 2009]

b. Die Mutter fleht an, dass der Richter vernünftig ?*ist/sei. DET madre rogar.3SG.IND, COMP DET juez sensato ser.3SG.IND/ser.3SG.SBJV I

'La madre ruega que el juez sea sensato'

c. Der Leiter fordert, dass der Elektriker fleißig ?*arbeitet/arbeite. DET director exigir.3SG.IND, COMP DET electricista diligente trabajar.3SG.IND/trabajar.3SG.SBJV I

'El director exige que el electricista trabaje diligentemente'

d. Der Leiter fordert, dass der Elektriker fleißig arbeiten *soll/solle. DET director exigir.3SG.IND, COMP DET electricista diligente trabajar deber.3SG.IND/deber.3SG.SBJV I

'El director exige que el electricista trabaje diligentemente'

El comportamiento de estos verbos resulta complicado. La oración (30a) con el verbo bitten (pedir) es considerada por la gramática alemana como una oración imperativa (Balcik, 2009); si el hablante desea dejar en claro que tal oración se inserta en el discurso indirecto no puede 
emplear el verbo subordinado en subjuntivo sino que es necesario incorporar el verbo modal sollen ${ }^{22}$ el cual a su vez debe aparecer en subjuntivo y no en indicativo. En (30b) aun cuando la oración se inserte en el discurso indirecto la alternancia entre indicativo y subjuntivo no es posible, por lo que el carácter de modalidad reportativa que podría aportar éste último modo no tiene efecto, en lugar de ello el empleo del subjuntivo aporta claramente el matiz de orden o petición, es decir, en este ejemplo la oración subordinada es en realidad una imperativa por lo que el potencial carácter reportativo no se manifiesta. El ejemplo (30c) es similar al anterior; la subordinada no puede adoptar el indicativo mientras que con el empleo del subjuntivo se obtiene una orden; una vez más la modalidad reportativa tampoco está presente. Si se deseara indicar de forma inequívoca que la oración pertenece al discurso indirecto habría que emplear de nuevo el verbo sollen que aparecería en subjuntivo (30d).

En conclusión, la aparición del subjuntivo en las subordinadas de los verbos exhortativos concuerda con el criterio que hemos venido observando ya que se trata de hechos que no han tenido lugar; más aún, para el cumplimiento de la petición solicitada se requiere de manera indispensable la participación de una tercera persona cuya voluntad evidentemente escapa del dominio del agente que realiza la petición. Aunque la aparición del subjuntivo sí es posible en estas oraciones es importante destacar que no refleja exactamente el matiz de irrealidad del evento y que tampoco posee por entero el carácter de modalidad reportativa. En su lugar, la interpretación más común sería considerar estas oraciones como imperativas exceptuando los casos donde se recurre al verbo sollen para indicar justamente que tales oraciones pertenecen al discurso indirecto. La pregunta entonces es ¿por qué con los verbos exhortativos el subjuntivo no puede expresar modalidad reportativa como hemos visto que

\footnotetext{
${ }^{22}$ sollen 'deber'; indica responsabilidad moral o consejo.
} 
sucede con otros grupos de verbos, por ejemplo, los reportativos? La respuesta parece sencilla pero habrá que considerarla con reservas. La modalidad reportativa permite al hablante tomar distancia cuando comunica la proposición que ha pronunciado una tercera persona; ésta proposición, a su vez, puede hacer referencia a cualidades que son permanentes, eventos o hechos que ya han tenido lugar o que podrán tenerlo en el futuro (30b). Todo lo anterior se engloba dentro del discurso indirecto, es decir, el hablante comunica lo que dijo alguien más. Ahora bien, tanto el agente que comunica una noticia, desde su conocimiento de los eventos o tras las conclusiones a las que haya llegado tras un proceso de razonamiento, así como el hablante que reproduce la noticia posteriormente, están en posición de considerar tal evento como real o falso; éste último puede elegir libremente entre indicativo y subjuntivo para marcar entonces modalidad reportativa. En el caso de los verbos exhortativos se hace referencia a un evento que no ha tenido lugar pero se espera que ocurra. Si esta consideración es correcta el valor reportativo que podría aportar el subjuntivo no puede expresarse porque se describe un evento que no ha ocurrido, pero existe la posibilidad de que se lleve a cabo. El problema, no obstante, persiste como se ve en los siguientes ejemplos:

a. Mein Vater denkt, mein Bruder kommt/komme morgen. mi padre pensar.3SG.IND, mi hermano venir.3SG.IND/venir.3SG.SBJV I mañana 'Mi padre piensa que mi hermano vendrá mañana'

b. Die Mutter fleht an, dass der Richter vernünftig DET madre rogar.3SG.IND, COMP DET juez sensato ser.3SG.IND/ser.3SG.SBJV I

'La madre ruega que el juez sea sensato'

Las dos oraciones de (31) indican eventos que no ha sucedido, pero se cree que sucederán (31a) o se anhela que sucedan (31b), sin embargo, en (31a) el subjuntivo sí aporta modalidad 
reportativa, pero no ocurre así en (31b). Otra alternativa que quizá nos permita entender por qué en (31b) el subjuntivo no refleja modalidad reportativa es mirar más de cerca el contenido semántico del verbo principal. Como se ha visto únicamente (31a) con el verbo creer puede aparecer en el discurso indirecto en el cual se reporta una proposición que fue expresada por una tercera persona. Es justamente esta característica por la que este tipo de discurso se asocia esencialmente con los verba dicendi y, en menor medida, pero también es posible, con los verbos que indican pensamiento u opinión; la alternancia entonces entre el modo indicativo y subjuntivo en el discurso indirecto es permitida con estos verbos.

Es necesario recordar en este punto que existe una diferencia importante en lo que hemos llamado reportativo y modalidad reportativa. El primero corresponde más o menos al discurso indirecto en el cual el hablante comunica una proposición, noticia o evento que una tercera persona mencionó con anterioridad; en este acto el hablante no agrega ningún juicio personal a la información que comunica; los verba dicendi son lo que generalmente se asocian a este tipo de discurso el cual a su vez no puede considerarse citativo. La estructura sintáctica de la forma discursiva que entendemos como cita corresponde a una oración principal que contiene el verbo reportativo y una subordinada que no es introducida por el complementante dass (que). Íntimamente relacionada con este acto discursivo tenemos a la modalidad reportativa. Bajo este rubro entendemos un tipo de actitud por parte del hablante en el cual no se compromete con la veracidad de la información que comunica a través del discurso indirecto, es decir, el hablante anuncia un hecho que expresó alguien más pero siempre tiene la posibilidad, en alemán, de considerar la información como verdadera para lo cual emplearía el indicativo en la oración complementante, o bien, puede no tomar responsabilidad sobre la 
veracidad o falsedad del evento que comunica, en cuyo caso la elección del subjuntivo refleja esa reserva que se quiere hacer patente durante el acto de habla. ${ }^{23}$ Como ya la mencionamos, la noción de modalidad reportativa la hemos adoptado de la propuesta que hiciera Matthews en 1965 cuando tras una investigación tipológica de la lengua Hidatsa ${ }^{24}$ logró identificar un morfema cuya función es justamente indicar que el hablante recibió la información de alguien más pero no tiene evidencia de su valor. En alemán, dentro del discurso indirecto, el subjuntivo tiene exactamente esa función pues permite al hablante indicar que el juicio que comunica no le pertenece y que no se responsabiliza por la veracidad del mismo.

Si volvemos ahora al ejemplo de (31b) nos daremos cuenta que el verbo rogar no introduce juicios ajenos sino que su tema argumental puede quedar manifiesto en una subordinada que indique petición o deseo. Si esta observación es correcta, podemos afirmar que el subjuntivo en la complementante de este verbo no puede aportar el matiz de modalidad reportativa del que hemos hablado, por el contrario, en alemán tiene una lectura de oración imperativa. En conclusión, el subjuntivo no puede reflejar aquí modalidad reportativa porque el verbo rogar no expresa ningún juicio u opinión del cual se pueda tomar distancia.

Ahora señalaremos en una tabla los resultados de nuestro análisis lo cual nos permitirá hacer algunas observaciones:

\footnotetext{
${ }^{23}$ El efecto más prominente de emplear el subjuntivo I es el hecho de indicar que el juicio de valor (más que considerarlo como verdadero o falso) no pertenece al hablante que lo comunica sino que fue pronunciado por una tercera persona.

${ }^{24}$ Lengua amerindia; su hablantes se localizan principalmente en Dakota del Norte.
} 


\begin{tabular}{|c|c|c|c|c|c|}
\hline & reportativos & desiderativos & dubitativos & opinión & exhortativos \\
\hline Indicativo & $\mathrm{X}$ & $\mathrm{X}$ & $\mathrm{X}$ & $\mathrm{X}$ & $\mathrm{X}$ \\
\hline Subjuntivo & $\mathrm{X}$ & & & $\mathrm{X}$ & \\
\hline
\end{tabular}

Modo que adopta preferentemente el verbo en alemán de la oración complementante de acuerdo a la semántica del verbo de la oración principal.

i) Únicamente los verbos reportativos y de opinión permiten la alternancia entre indicativo y subjuntivo. No obstante, recordemos que este comportamiento no se relaciona directamente con el criterio base que mencionamos al principio y que hemos seguido durante el análisis; la alternancia aquí no obedece estrictamente al hecho de que una proposición se considere real (indicativo) o sea vista como un evento potencial o hipotético (subjuntivo). La alternancia de modo obedece más bien al efecto pragmático que desea lograr el hablante dentro del discurso indirecto. Es necesario advertir que este hallazgo no es nuevo puesto que los estudios del subjuntivo alemán ya lo han mencionado con anterioridad; más aún, se trata de una descripción que aparece en las gramáticas actuales (Balcik 2009, Corcoll 2001). Sin embargo, con el fin de justificar nuestro objetivo (identificar plenamente y categorizar el valor modal del subjuntivo I), era necesario realizar el análisis del comportamiento del modo verbal en las oraciones complementantes, ya que, además de identificar todos los factores relacionados, intentamos identificar si en la actualidad el valor de modalidad reportativa del subjuntivo I alemán se está consolidando como tal a la vez que pierde sus otras aplicaciones. 
ii) En el caso de los verbos que hemos agrupado como desiderativos y dubitativos observamos en los ejemplos que únicamente aceptan el indicativo en sus oraciones complementantes, lo cual no concuerda con el criterio de uso que hemos mencionado. Más aún, es un hecho que sirve de contraste con la observación anterior pues deja en claro que el subjuntivo I aparece exclusivamente en las oraciones complementantes de los verbos que se emplean dentro del discurso indirecto, a saber los verba dicendi o reportativos y el grupo que hemos clasificado como de opinión.

iii) Con los verbos exhortativos, la aparición del subjuntivo en la oración subordinada tiene una lectura de oración imperativa aunque en el caso de los verbos como rogar se interpreta más bien como un deseo (31b). Si el hablante desea indicar explícitamente que estas oraciones se insertan en el discurso indirecto hay que recurrir al verbo modal sollen que debe aparecer entonces en subjuntivo.

Hasta este punto hemos abordado el análisis del contexto de aparición del subjuntivo I alemán en oraciones subordinadas tomando como base la descripción inicial sobre el empleo de los modos indicativo y subjuntivo. Los resultados nos demostraron que el subjuntivo I aparece, con la lectura de modalidad reportativa, exclusivamente con los verba dicendi y los de opinión, un hecho que ya ha sido descrito anteriormente pero que constituye un punto de avance en nuestra investigación al constatar que, en efecto, el subjuntivo I se presenta preferentemente en el discurso indirecto en donde su función es aportar ese matiz de modalidad del que hemos hablado anteriormente. 
Por otro lado, si bien es cierto que en los intentos de categorización sobre el empleo de los modos verbales se ha visto la actitud del hablante como el factor que determina el uso de uno u otro —en el caso del indicativo y subjuntivo la dicotomía real-irreal actualmente sigue siendo tomada en cuenta - otras propuestas de análisis consideran ciertas nociones pragmáticas que al parecer, y es justamente lo que queremos comprobar, pueden predecir de mejor manera no sólo el contexto sintáctico de aparición del subjuntivo I en estas oraciones complementantes, sino también revelar si en efecto se le puede seguir adjudicando a este modo el valor de modalidad reportativa. Es por ello que en esta segunda parte introducimos las nociones de factividad y asertividad (Kiparsky, 1970; Kartunnen, 1973) para después analizar las oraciones que englobaremos en cada una de estas dos nociones.

Es conveniente destacar que en la teoría lingüística en español todavía no existe un consenso sobre estos dos términos ya que en ocasiones son considerados incluso como sinónimos. Sin embargo, recientes análisis como los de Kellner (2013), sí marcan una diferencia entre ambos, por lo que consideramos pertinente tener bien en claro estos dos conceptos para las cuales proponemos las siguientes definiciones:

Factividad: el hablante comunica una proposición que sostiene como un hecho real e innegable. Pertenecen a esta categoría verbos que contenga como trasfondo un proceso epistemológico sólido: saber, comprender, concluir, conocer, aceptar.

$$
\text { a. Er weiss, dass die Erde rund ist } /{ }^{*} \text { sei. }
$$
él saber.3SG.IND, COMP DET tierra redonda ser.3SG.IND/ser.3SG.SBJV I 'Él sabe que la tierra es redonda' 

b. Erversteht, dass der Mond um die Erde $\mathbf{k r e i s t}{ }^{*}$ kreise. él comprender.3SG.IND, COMP DET luna alrededor DET tierra girar.3SG.IND/ser.3SG.SBJV I
'Él comprende que la luna gira alrededor de la tierra'

c. Er nimmt an, dass die Erde nicht im Zentrum des Sonnensystems steht $/{ }^{*}$ stehe.

él aceptar.3SG.IND, COMP DET tierra NEG en el centro del sistema solar estar.3SG.IND/estar.3SG.SBJV I

'Él acepta que la tierra no está en el centro del sistema solar'

Ninguno de los verbos de (32) acepta el subjuntivo en sus oraciones complementantes. Esta observación nos permite aseverar que el empleo del indicativo en estos ejemplos obedece al hecho de que el sujeto de la oración considera su juicio como real y certero, y no como un evento hipotético. En este sentido la aparición del indicativo concuerda enteramente con el criterio básico (real - irreal) que intenta predecir la aparición de los modos verbales.

En alemán no es posible el subjuntivo I en la subordinada ya que, por un lado, tales verbos factivos no se pueden insertan en el discurso indirecto por lo que el valor de modalidad reportativa no está presente; incluso si el subjuntivo I pudiera ser empleado en esta forma discursiva para reflejar cierto carácter hipotético de la proposición entraría en conflicto entonces con la semántica de los verbos principales que son factivos, y cuyo significado es precisamente expresar juicios o conocimientos que se consideran certeros.

Asertividad: el hablante se compromete con, o más bien afirma, la veracidad de la proposición que comunica. A diferencia de los verbos factivos esta clase de verbos no refleja una certeza total, sino que puede haber un mínimo grado de incertidumbre, razón por la cual se pueden subdividir a su vez en: 
i) Asertivos fuertes como asegurar, comunicar, afirmar, decir, narrar, advertir.

a. Er versichert, dass die Frau unschuldig ist/sei. él asegurar.3SG.IND, COMP DET mujer inocente ser.3SG.IND/ser.3SG.SBJV I 'Él asegura que la mujer es inocente'

b. Er sagt, dass Peter keinen Alkohol trinkt/trinke. él decir.3SG.IND, COMP Pedro ningún alcohol beber.3SG.IND/ser.3SG.SBJV I 'Él dice que Pedro no bebe alcohol'

c. Erwarnt, dass die Schlangen gefährlich sind/seien. él advertir.3SG.IND, COMP DET serpientes peligrosas ser.3SG.IND/ser.3SG.SBJV I 'Él advierte que las serpientes son peligrosas'

Esta subcategoría de verbos asertivos, cuando se insertan dentro del discurso indirecto, pueden adoptar libremente el indicativo 0 subjuntivo en sus oraciones complementantes. Entonces la alternancia entre los dos modos marcará la postura con respecto el juicio referido; como ya se ha explicado el empleo del subjuntivo I refleja el matiz de modalidad reportativa.

ii) Asertivos débiles como creer, pensar, considerar.

a. Er glaubt, dass die Frau unschuldig ist/sei. él creer.3SG.IND, COMP DET mujer inocente ser.3SG.IND/ser.3SG.SBJV I 'Él cree que la mujer es inocente'

b. Er denkt, dass die Erde rund ist/sei. él pensar.3SG.IND, COMP DET tierra redonda ser.3SG.IND/ser.3SG.SBJV I 'Él piensa que la tierra es redonda'

c. Er schätzt, dass Ana viel Glück hat $/$ habe. él considerar.3SG.IND, COMP Ana mucho suerte tener.3SG.IND/ser.3SG.SBJV I 'Él considera que Ana tiene mucha suerte'

En el caso de los verbo asertivos débiles los hemos denominado así porque de acuerdo a su contenido semántico reflejan un grado de incertidumbre ligeramente mayor que los asertivos 
fuertes. El empleo del subjuntivo en sus oraciones complementantes es posible, y aunque presenta el mismo valor que muestra con los asertivos fuertes, a saber, la modalidad reportativa, es necesario mencionar que el empleo del subjuntivo con esta clase de verbos es más usual en el lenguaje cuidado y no es tan común en el habla cotidiana (Barcik, 2009); con todo el valor de modalidad reportativa permanece.

¿Por qué los verbos que hemos clasificado como asertivos fuertes sí pueden adoptar sin restricciones el subjuntivo en alemán a diferencia de los débiles? ¿Corresponde sólo a una cuestión de estilo en el habla? ¿Cuál sería la diferencia semántica entre afirmar y creer? Es indudable que ambos verbos poseen un distinto grado de certeza pero esta característica no puede pronosticar satisfactoriamente la aparición del indicativo o subjuntivo, por el contrario, la predicción sería incorrecta; si el verbo es asertivo débil tendría que aceptar sin ninguna restricción y preferentemente el subjuntivo puesto que el grado de incertidumbre intrínseco es mayor; por su parte, el asertivo fuerte difícilmente lo haría.

La siguiente observación posiblemente nos acerque a una respuesta aceptable. Todos los verbos que hemos agrupado como asertivos fuertes comunican algo a alguien, o, en términos semánticos, pueden tomar un destinatario (recipient) además de su tema: (Le) aseguró (al juez) que Pedro no bebe alcohol; (le) advirtió (a los exploradores) que las serpientes son peligrosas. Además esta categoría de verbos fuertes contiene los tradicionales verba dicendi lo cuales de hecho sí permiten la alternancia entre ambos modos por lo cual la modalidad reportativa se presenta sin problemas enmarcada además por el discurso indirecto en donde el hablante que comunica puede estar de acuerdo o no con la proposición que ha escuchado de una tercera persona. Por el contrario en los verbos asertivos débiles hay cierto grado de 
incertidumbre que es inherente al significado propio del verbo, así que la modalidad reportativa que introduce el subjuntivo en la oración complementante reforzaría aún más la distancia que el hablante quisiera tomar respecto al juicio emitido por una tercera persona, sin embargo, el subjuntivo no resulta indispensable, porque este distanciamiento ya está marcado en cierta forma por el verbo principal como sucede, por ejemplo, con creer. En efecto, el agente que escucha considerará que hay mayor certeza sobre lo referido en la oración Juan asegura que Ana está enferma que en Juan cree que Ana está enferma.

Como vimos, únicamente los verba dicendi y los de opinión permiten la alternancia de modos. Hay en ellos una característica que refuerza el contexto donde puede aparecer el subjuntivo: el hablante comunica lo que dijo una tercera persona, lo cual le permite de facto tomar distancia con respecto al juicio emitido, por lo tanto, la primera persona nunca puede aparecer como sujeto de la oración principal si el verbo de la subordinada está en subjuntivo:

a. Er sagt, dass Hans krank ist/sei. él decir.3SG.IND, COMP Juan enfermo estar.3SG.IND/estar.3SG.SBJV I 'Él dice que Juan está enfermo'

b. Ich sage, dass Hans krank ist $/{ }^{*}$ sei. yo decir.1SG.IND, COMP Juan enfermo estar.3SG.IND/estar.3SG.SBJV I 'Yo digo que Juan está enfermo'

Ahora bien, en todos los casos la subordinada puede aparecer con o sin el complementante dass, y aunque el contenido es el mismo se percibe un efecto pragmático distinto:

a. Er sagt, dass die Partei in Krise ist. él decir.3SG.IND, COMP DET partido en crisis estar3SG.IND 'Él dice que el partido está en crisis' 
b. Er sagt, dass die Partei in Krise sei.

él decir.3SG.IND, COMP DET partido en crisis estar3SG.SBJV I

'Él dice que el partido está en crisis'

c. Er sagt, die Partei ist in Krise.

él decir.3SG.IND, DET partido estar3SG.IND en crisis

'Él dice que el partido está en crisis'

d. Er sagt, die Partei sei in Krise.

él decir.3SG.IND, DET partido estar3SG.SBJV I en crisis

'Él dice que el partido está en crisis'

Para demostrar que el valor pragmático de estas cuatro oraciones no es el mismo, podríamos crear un rasgo binario que contenga el rasgo [ \pm reportativo] si el verbo subordinado aparece en indicativo [-reportativo] o subjuntivo [+reportativo], y el rasgo [ \pm citativo] si aparece el complementante dass [-citativo] o no [+citativo]:

a. Er sagt, dass die Partei in Krise ist. $\quad[-R][-C]$

b. Er sagt, dass die Partei in Krise sei. [+ R][- C]

c. Er sagt, die Partei ist in Krise. [- R][+ C]

d. Er sagt, die Partei sei in Krise. $\quad$ [+ R][+ C]

Esta forma de explicar el fenómeno tiene la ventaja de que los valores positivos o negativos dan mejor cuenta del valor pragmático de toda la oración; algunas propuestas han tratado de ubicar estos valores en una escala continua, pero por la naturaleza misma del método sería difícil delimitar exactamente donde termina un valor y empieza el otro. Con nuestro rasgo binario podemos dejar más en claro que una oración puede presentar modalidad reportativa y que la estructura sintáctica de la misma puede tomar forma de una cita. Por consiguiente, el 
valor modal de la oración no sólo depende del modo que elija el complemento, que está determinado a su vez por la semántica del verbo, sino también de la disposición sintáctica de los elementos. Este es un hallazgo de suma importancia para nuestro trabajo porque confirma una de nuestras hipótesis iniciales de investigación, a saber, el valor de modalidad que se le puede adjudicar al subjuntivo I alemán dentro del discurso indirecto depende de una serie de factores tanto semánticos como sintácticos y, en última instancia, no está determinado únicamente por el modo verbal en sí, sino que depende del comportamiento de estos factores en conjunto. 


\section{INDICADORES LÉXICO-SEMÁNTICOS DE MODALIDAD EN ALEMÁN Y SU INTERACCIÓN CON EL SUBJUNTIVO I}

En este último capítulo se detallarán brevemente algunos otros recursos que posee el alemán para expresar distintos tipos de modalidad; particularmente se pondrá énfasis en su interacción con el subjuntivo I cuando éste adopta o expresa la modalidad reportativa que adquiere dentro del discurso indirecto.

\section{Verbos modales}

El alemán cuenta con un sistema de verbos modales que se pueden clasificar de la siguiente manera de acuerdo con la propuesta de von Fintel (2006):

\begin{tabular}{|l|l|}
\hline Modalidad dinámica: & können \\
\hline Modalidad deóntica: & dürfen, sollen, müssen \\
\hline Modalidad epistémica: & sollen, müssen, mögen \\
\hline Modalidad bulética: & wollen, mögen \\
\hline
\end{tabular}

En (38a) el verbo principal expresa modalidad dinámica que indica la capacidad o habilidad física del agente que realiza la acción; en (38b) el mismo verbo indica una posibilidad de que una acción se pueda llevar a cabo dentro de un contexto determinado:

a. Er kann Deutsch sprechen. 3SG poder.3SG.IND alemán hablar ‘Él sabe (puede) hablar alemán'

b. Auf dem Markt kann man Tomaten kaufen. sobre DET.M.DAT mercado poder.3SG.IND PRON.IMP tomates comprar 'En el mercado se pueden comprar tomates' 
Por su parte todos los ejemplos de (39) muestran modalidad deóntica que es aquella que expresa lo que es necesario, posible, prohibido o aconsejable en contextos que se insertan en un marco de leyes sociales que rigen o dictan el comportamiento del individuo en un momento determinado de la historia. Así por ejemplo en (39a) tenemos una prohibición, en (39b) un consejo y en un (39c) una necesidad que resulta imperiosa dadas las circunstancias.

a. Sie dürfen hier nicht rauchen. 3PL poder.3PL aquí NEG fumar 'Usted no puede fumar aquí (no está permitido)'

b. Du sollst keinen Schnaps trinken. 2SG deber.2SG NEG.M.ACC licor beber

'Tú no debes beber licor (no es aconsejable)'

c. Sie müssen sofort das Gebäude verlassen. Es ist ein Brand. incendio 3PL deber.3PL enseguida DET edifico abandonar. 3SG ser.3SG.IND DET

'Usted debe abandonar de inmediato el edificio; hay un incendio'

La modalidad epistémica es la que tiene como base el conocimiento o la inferencia del individuo que comunica una proposición. Así tenemos que en (40a) el verbo modal nos indica que el individuo formula una suposición con base en su conocimiento de los hechos que han ocurrido, y en (40b) se trata de una inferencia que de la misma forma toma como base ciertos indicios para formular una conjetura:
a. Es
soll
letzte Woche sein,
als
ich sie
getroffen habe.
3SG. deber.3SG.IND última semana ser.INF, CONJ 1SG 3SG.F.ACC encontrar.PTCP haber.1SG.PRES.IND
'Debió ser la semana pasada cuando la vi' 
b. Er muss viel Geld haben. Er besitzt ein Ferrari. 3SG deber.3SG.IND mucho dinero tener.INF. 3SG poseer.3SG.IND DET Ferrari 'Debe de tener mucho dinero. Es dueño de un ferrari'

Por último en los ejemplos de (41) se aprecia la modalidad bulética que es aquella que indica los deseos (41a) o inclinaciones del individuo (41b). En este punto cabe mencionar que es evidente que un mismo verbo modal aporta diversos matices de modalidad, de tal suerte que para saber con certeza el tipo de modalidad que expresa es necesario considerar el contexto en que se formulan tales oraciones.

a. Ich will ein Eis, bitte. 1SG querer.1SG DET helado, favor 'Quiero un helado por favor'

b. Hans mag Hunde. Juan gustar.3SG.IND perro.PL 'A Juan le gustan los perros'

\section{Preposiciones}

Como mencionamos en el capítulo 2.3 en alemán hay una sola preposición que puede lograr el efecto de modalidad que se relaciona con el uso del subjuntivo porque su función básica es justamente introducir el discurso indirecto. La preposición laut, tal y como sucede con el empleo del subjuntivo I, marca distancia respecto a la noticia que se comparte. Hay que notar, no obstante, que dicha preposición no puede aparecer si el verbo de la oración está en subjuntivo (42a). Sin embargo, cuando laut introduce una frase prepositiva (42b), el verbo de la oración subordinada puede tomar el subjuntivo aunque no es claro si el valor de modalidad reportativa está presente. 

a. $\mathrm{Er}$ ist $/{ }^{*} \mathbf{s e i}$
laut ärztlicher
Diagnose völlig
gesund. 3SG ser.SG.IND/SBJV I PREP médico.F.GEN diagnóstico completamente sano 'De acuerdo con el diagnóstico médico (él) está complemente sano'

b. Laut des geschossen.

Verbrechers, er ?habe/hat nicht PREP DET.M.GEN criminal.GEN, 3M.SG. haber.3SG.SBJVI/IND NEG PTCPdisparar 'Según el criminal, él no habría disparado/disparó'

(Balcik (2009): 274)

\section{Adverbios y otras partículas modales}

De la lista de partículas modales ${ }^{25}$ que ofrece Corcoll (2001) en su gramática alemana hemos seleccionado, las que a nuestro juicio, se relacionan de manera más estrecha con el discurso indirecto y, por consiguiente, con el efecto de distanciamiento que se logra con el empleo del subjuntivo I. Para apreciar mejor el significado de estas partículas las colocaremos en una escala en cuyos extremos aparece por un lado la incertidumbre y en el otro la total certeza sobre el evento que se comunica. En los ejemplos se verá también si es posible que dichas partículas, en especial las que indican duda, pueden aparecer con el subjuntivo I para reforzar el distanciamiento pragmático.

Incertidumbre Certeza vermutlich vielleicht wohl wahrscheinlich möglich zweifellos bestimmt sicher

\footnotetext{
${ }^{25}$ Aquí consideramos como partículas modales aquellos adverbios u otros ítems léxicos cuya función es aportar cierto matiz de modalidad a las oraciones en las que aparecen.
} 
a. Er hat/*habe vermutlich viel Geld. 3SG tener.3SG.IND/SBJV I supuestamente mucho dinero 'Supuestamente (él) tiene mucho dinero'

b. Vielleicht kommt/komme er auf die Party. quizás venir.3SG.IND/SBJVI 3SG a DET fiesta 'Quizás venga él a la fiesta'

c. Er ist ${ }^{*}$ sei wohl 25 Jahre alt. 3SG ser.3SG.IND/SBJV I quizás 25 años viejo 'A lo mejor tiene 25 años'

d. Wahrscheinlich ist/*sei sie unschuldig. Probablemente ser.3SG.IND/SBJV I 3SG.F inocente 'Probablemente ella sea inocente'

e. Es ist $/{ }^{*}$ sei möglich, dass ich nächste Woche nach Deutschland reise. 3SG ser.3SG.IND/SBJV I posible, COMP 1SG próxima semana hacia Alemania viajar.1SG.IND

'Es posible que vaya (yo) la próxima semana a Alemania'

f. Der Leiter ist ${ }^{*}$ sei zweifellos eine richtige Person.

DET director ser.3SG.IND/SBJV I sin duda DET correcta persona

'El director es sin duda una persona honrada'

g. Hab Geduld, er kommt/*komme bestimmt. tener.2SG.IMP paciencia, 3SG venir.3SG.IND/SBJV I ciertamente 'ten paciencia, seguro viene/*venga (él)'

h. Ich bin/*sei sicher, dass du die Wahrheit sagst.

1SG ser.3SG.IND/SBJV I seguro, COMP 2SG DET verdad decir.2SG.IND 'Estoy seguro de que dices la verdad'

Todos los ejemplos de (43) muestran que las partículas modales no permiten el subjuntivo en los verbos de las oraciones que acompañan. Este es un hallazgo que resulta sorprendente en especial si se compara con el español, el cual sí permite el uso del subjuntivo con algunas partículas modales como se aprecia en las glosas. 


\section{Verbos modales en subjuntivo}

Son raros los ejemplos de verbos modales que adopten la forma del subjuntivo; además es necesario mencionar que la combinación del subjuntivo con los verbos modales logra efectos que, si bien pueden catalogarse como categorías de modalidad, al parecer no se relacionan directamente con el distanciamiento que otorga el subjuntivo en el discurso indirecto.

a. Rau hatte Amt zu bleiben.

mit Engholm gesprochen und ihm

geraten, im

Rau haber.3SG.PAST PREP Engholm hablar.PTCP y 3SG.DAT aconsejar.PTCP, LOC servicio PREP permanecer.

Doch müsse er selbst die Entscheidung treffen.

Pero deber.3SG.SBJVI 3SG mismo DET decisión encontrar decidirlo'

'Rau había hablado con Engholm y le aconsejó permanecer activo. Sin embargo, sólo él podía

b. Doch vor dem Interview teilte man mir mit, was ich sagen dürfe.

Justo antes DET.N.DAT entrevista compartir.3SG.PAST IMP 1SG.DAT PREF, CONJ 1SG decir poder.1SG.SBJV I

'Justo antes de la entrevista me informaron lo que podía decir (lo que estaba permitido)'

c. Ich bat

Dr. Stroncickij, er möge

doch kurz in mein

Büro kommen.

1SG pedir.1SG.PAST Dr. Stroncickij, 3SG gustar.3SG.SBJV I pero breve PREP POSS.1SG oficina venir

'Le pedí al Dr. Stroncickij que viniera un momento a mi oficina'

(Fabricius-Hansen (2004): 214, 220)

De acuerdo con Fabricius-Hansen el subjuntivo que aparece en el verbo modal de (44a) tendría una función de presuposición reportativa más que indicar distanciamiento por parte del hablante. Por su parte en el ejemplo (44b) tenemos que el verbo modal en subjuntivo aparece en una pregunta indirecta aunque según Hansen se trata de cualquier forma de una aserción. 
Por último en (44c) vemos una oración directiva ${ }^{26}$, y se considera que el subjuntivo del verbo modal aquí tiene la función pragmática de expresar la orden con un matiz menos severo.

\section{Conclusiones}

La fenomenología concreta del subjuntivo I alemán requirió para su análisis retomar primeramente algunas propuestas tradicionales de categorización de los modos indicativo y subjuntivo. Más tarde, en vista de que tales acercamientos resultaron insuficientes para abordar a fondo el uso particular de esta forma del subjuntivo, insuficiencia que quedó demostrada aún en el caso de la alternancia de modos en español, recurrimos entonces a nociones pragmáticas más modernas para trata de identificar plenamente el valor modal del subjuntivo I, a saber, factividad y asertividad. Sin embargo, nuestro análisis no podía quedar completo en ese punto puesto que, como hemos advertido, el empleo actual del subjuntivo I, y consecuentemente su valor efectivo, se encuentra estrechamente relacionado con otros factores como el contexto discursivo donde aparece, discurso indirecto; la modalidad que puede reflejar en ese entorno, modalidad reportativa, que a su vez se puede contraponer al carácter citativo; y una serie de elementos sintácticos como el complementante dass y los indicadores léxico-semánticos que analizamos en el último capítulo. Enumeraremos ahora las conclusiones obtenidas de este trabajo:

\footnotetext{
${ }^{26}$ Esta nomenclatura de las oraciones es de la traducción directa del texto que se cita. En los ejemplos lo que es importante para nosotros es hacer notar que los verbos modales en subjuntivo I adquieren otro matiz distinto al efecto de distanciamiento que estamos analizando.
} 
I. De acuerdo con nuestra investigación es legítimo adjudicarle al subjuntivo I alemán un valor propio de modalidad, no obstante, este valor, aunque pleno no puede aparecer de manera independiente sino que inserta en un contexto discursivo particular.

II. El valor de modalidad del subjuntivo I únicamente resulta efectivo en el discurso indirecto, en el cual el hablante comunica una opinión que le es ajena. En este caso el subjuntivo I aparece exclusivamente en las oraciones complementantes de los verbos que hemos clasificado como verba dicendi y verbos de opinión, y su función primordial no es expresar el carácter de irrealidad del evento sino aportar el carácter de modalidad reportativa de acuerdo con la propuesta de Matthews (1965).

III. El subjuntivo I puede ser considerado como un modo verbal entendido como un recurso gramatical que posee el alemán para expresar el tipo de modalidad que hemos caracterizado aquí, es decir, modalidad reportativa. No obstante, aunque el subjuntivo I se asocia frecuentemente con este tipo de modalidad no se trata de una asociación exclusiva, sino que este modo puede adquirir otros valores que, sin embargo, hoy en día son poco frecuentes con excepción de las formas del verbo sein (ser, estar) que pueden aparecer en oraciones directivas; lo anterior es un hecho que nos indica que probablemente en el futuro el subjuntivo I alemán tendrá como única función expresar la modalidad que hemos caracterizado. 
IV. La modalidad reportativa que adquiere el subjuntivo I sólo es posible cuando el sujeto de la oración es distinto del hablante que refiere la información (discurso indirecto). El hecho de que el sujeto sea una tercera persona permite al hablante tomar distancia respecto al juicio emitido mientras que no podría hacerlo, al menos no con la modalidad que aporta el subjuntivo I, si el juicio que comunica le pertenece.

V. Las nociones de factividad y asertividad nos han proporcionado una herramienta mucho más precisa para predecir la aparición del modo verbal en las oraciones complementantes. Los verbos factivos siempre se relacionan con el indicativo, mientras que en el caso de los asertivos pueden adoptar indicativo o subjuntivo sin importar las restricciones de la semántica del verbo principal. Las dos clases de verbos que introducen el subjuntivo I se relacionan a su vez con los verbos asertivos fuertes (verba dicendi) como decir, y los asertivos débiles (verbos de opinión) como pensar, creer. En este punto la elección de modo depende del efecto pragmático (modalidad reportativa) que desee o no expresar el hablante.

VI. La modalidad reportativa del subjuntivo I alemán quedó demostrada de mejor manera cuando la consideramos como un valor que puede estar en contraposición con el citativo. En este punto el rasgo binario [ \pm reportativo] [ \pm citativo] delimita exactamente donde existe modalidad reportativa y donde la oración se puede considerar una cita. Si expusiéramos los valores en una escala lineal las fronteras entre uno y otro no quedarían bien delimitadas. 
VII. El subjuntivo I puede adoptar valor de modalidad reportativa pero depende de los siguientes factores:

a) Insertarse en el discurso indirecto.

b) Aparecer como complemento de verbos reportativos, es decir, los verba dicendi y de opinión.

c) El complementante dass cuya ausencia o presencia favorece o no la interpretación de modalidad como quedó demostrado en la escala binaria donde los valores de modalidad reportativa y citativo se contraponen.

VIII. La propia aparición del subjuntivo I se ve restringida por los siguientes elementos:

a) La preposición laut para introducir un juicio ajeno o disposición oficial no permite el subjuntivo I sino el indicativo.

b) Los adverbios que introducen certeza o incertidumbre tampoco permiten la aparición del subjuntivo I sino que eligen el modo indicativo.

IX. Si bien los verbos modales pueden tomar la forma del subjuntivo, el efecto de modalidad es otro distinto al que el subjuntivo I logra en el discurso indirecto. 


\section{Bibliografía}

Aikhenvald. 2006. Arawak Languages (article 2292) of Encyclopedia of Language and Linguistics, 2nd Edition, edited by Keith Brown. Elsevier: Oxford.

Balcik, Ines et al. 2009. Perfektes Deutsch. Der Ratgeber in sprachlichen Zweifelsfällen. PONS GmbH, Stuttgart.

Bayerová, Marcela. Verbos asertivos y su comportamiento en el español mexicano. Universitatis Brunensis, 1996.

Beristáin, Helena. 2003. Diccionario de retórica y poética. Ed. Porrúa, México D.F.

Bolinger, Dwight. 1968. "Postposed Main Phrases: An English Rule for the Romance Subjunctive," Canadian Journal of Linguistics, 14, 3-30.

Bybee, Joan L. 1994. The evolution of grammar: tense, aspect and modality in the languages of the world. Joan Bybee, Revere Perkins and Wiliam Pagliuca. The University Chicago Press, Chicago.

Comrie, Bernard. 1976. Aspect. Cambridge: Cambridge University Press.

Corcoll, Brigitte y Roberto Corcoll. 2001. Gramática. Alemán para hispanohablantes. Ed. Herder, Madrid.

Cruse, Alan. 2011. Meaning in Language. An introduction to semantics and pragmatics. Oxford: Oxford University Press.

De Haan, Ferdinand. 2001. "The Relation between Modality and Evidentiality". En Linguistische Berichte Sonderheft 9:201-216

De Haan, Ferdinand. 2005. "Typological approaches to modality". En W. Frauley (ed.), Modality, Berlin: Mouton de Gruyter.

Fabricius-Hansen, Cathrine y Johan Saebö. 2004. "In a mediative mood: The semantics of the German reportive subjunctive". En Natural Language Semantics 12: 213-257

Kartunnen, Lauri. Presupposition and Linguistic Context. University of Texas, 1973.

Kartunnen, Lauri. "Presupposition of Compound Sentences", en Linguistic Inquiry Volume IV Number 2, 1973, 169-193.

Kellner, Elisa y Lukasz Jedrzejowski. 2013. "Towards a unified account of the force triggering subjunctive complements". En Tampere Linguistics Forum. ZAS, Berlin. 
Lunn, Patricia V. 1995. "The evaluative function of the Spanish subjunctive". En Bybee and Fleischmann 1995: 419-49

Mithun, Marianne. 1999. The languages of Native North America. Cambridge: Cambridge University Press.

Palmer, F. R. 2001. Mood and modality. Cambridge: Cambridge University Press.

Searle, J. R. 1983. Intentionality. Cambridge: Cambridge University Press.

Thieroff, Rolf. 2010. "Moods, moods, moods". En B. Rothstein y R. Rolf Mood The languages of Europe, John Benjamins pp. 1-29.

Von Fintel, Kai 2006. "Modality and Language". En D. Borchert (ed.). Encyclopedia of Philosophy. New York: Macmillan. 